\title{
Enhanced Functional Activity of the Cannabinoid Type-1 Receptor Mediates Adolescent Behavior
}

\author{
Miriam Schneider, ${ }^{1,2}$ Fernando Kasanetz, ${ }^{3,4}$ Diane L. Lynch, ${ }^{5}$ Chris M. Friemel, ${ }^{2}$ Colivier Lassalle, ${ }^{6,7,8}$ Dow P. Hurst, ${ }^{5}$ \\ Frauke Steindel, ${ }^{9}$ CKrisztina Monory, ${ }^{9}$ Carola Schäfer, ${ }^{10,11}$ Isabelle Miederer, ${ }^{12}{ }^{\circ}$ F. Markus Leweke, ${ }^{10}$ \\ Mathias Schreckenberger, ${ }^{12}$ Beat Lutz, ${ }^{9}$ Patricia H. Reggio,,${ }^{5}$ Olivier J. Manzoni, ${ }^{6,7,8}$ and Rainer Spanagel ${ }^{1}$ \\ ${ }^{1}$ Institute of Psychopharmacology and ${ }^{2}$ Research Group Developmental Neuropsychopharmacology, Institute of Psychopharmacology, Central Institute of \\ Mental Health, Medical Faculty Mannheim, Heidelberg University, 68159 Mannheim, Germany, ${ }^{3}$ INSERM, Neurocentre Magendie, and ${ }^{4}$ University of \\ Bordeaux, Neurocentre Magendie, Physiopathologie de la Plasticité Neuronale, U862, F-33000 Bordeaux, France, ${ }^{5}$ Center for Drug Discovery, Department \\ of Chemistry and Biochemistry, University of North Carolina, Greensboro, North Carolina 27402, ${ }^{6}$ INSERM, U901, Marseille 13009, France, ${ }^{7}$ Université de \\ la Méditerranée, UMR S901 Aix-Marseille 2, France, ${ }^{8} \mathrm{INMED}$, Marseille 13009, France, ${ }^{9}$ Institute of Physiological Chemistry, University Medical Center of \\ the Johannes Gutenberg University Mainz, 55128 Mainz, Germany, ${ }^{10}$ Department of Psychiatry and Psychotherapy, Central Institute of Mental Health, \\ Medical Faculty Mannheim, Heidelberg University, 68159 Mannheim, Germany, ${ }^{11}$ Department of Psychiatry and Psychotherapy, University of Cologne, \\ 50924 Cologne, Germany, and ${ }^{12}$ Department of Nuclear Medicine, University Medical Center of the Johannes Gutenberg University Mainz, 55131 Mainz, \\ Germany
}

Adolescence is characterized by drastic behavioral adaptations and comprises a particularly vulnerable period for the emergence of various psychiatric disorders. Growing evidence reveals that the pathophysiology of these disorders might derive from aberrations of normal neurodevelopmental changes in the adolescent brain. Understanding the molecular underpinnings of adolescent behavior is therefore critical for understanding the origin of psychopathology, but the molecular mechanisms that trigger adolescent behavior are unknown. Here, we hypothesize that the cannabinoid type-1 receptor (CB1R) may play a critical role in mediating adolescent behavior because enhanced endocannabinoid (eCB) signaling has been suggested to occur transiently during adolescence. To study enhanced CB1R signaling, we introduced a missense mutation (F238L) into the rat $\mathrm{Cnrl}$ gene that encodes for the CB1R. According to our hypothesis, rats with the F238L mutation $\left(\mathrm{Cnrl}^{\mathrm{F} 238 \mathrm{~L}}\right)$ should sustain features of adolescent behavior into adulthood. Gain of function of the mutated receptor was demonstrated by in silico modeling and was verified functionally in a series of biochemical and electrophysiological experiments. Mutant rats exhibit an adolescent-like phenotype during adulthood compared with wild-type littermates, with typical high risk/novelty seeking, increased peer interaction, enhanced impulsivity, and augmented reward sensitivity for drug and nondrug reward. Partial inhibition of $\mathrm{CB} 1 \mathrm{R}$ activity in $\mathrm{Cnr}{ }^{\mathrm{F} 238 \mathrm{~L}}$ mutant rats normalized behavior and led to a wild-type phenotype. We conclude that the activity state and functionality of the $\mathrm{CB} 1 \mathrm{R}$ is critical for mediating adolescent behavior. These findings implicate the eCB system as an important research target for the neuropathology of adolescent-onset mental health disorders.

Key words: adolescence; $\mathrm{CB} 1$ receptor; endocannabinoids; ENU mutagenesis; reward processing; risk seeking

Significance Statement

We present the first rodent model with a gain-of-function mutation in the cannabinoid type-1 receptor (CB1R). Adult mutant rats exhibit an adolescent-like phenotype with typical high risk seeking, impulsivity, and augmented drug and nondrug reward sensitivity. Adolescence is a critical period for suboptimal behavioral choices and the emergence of neuropsychiatric disorders. Understanding the basis of these disorders therefore requires a comprehensive knowledge of how adolescent neurodevelopment triggers behavioral reactions. Our behavioral observations in adult mutant rats, together with reports on enhanced adolescent CB1R signaling, suggest a pivotal role for the CB1R in an adolescent brain as an important molecular mediator of adolescent behavior. These findings implicate the endocannabinoid system as a notable research target for adolescent-onset mental health disorders. 


\section{Introduction}

Adolescence, the transitional stage between childhood and adulthood, is characterized by drastic processes of neuronal architecture and function involving mainly maturational processes in cortical networks and limbic regions (Spear, 2000; Casey et al., 2008). These neuronal changes result in adolescent behavioral characteristics that can be observed in various mammalian species (Spear, 2000). Adolescent behavioral characteristics include high risk/novelty seeking, the development of social skills, impulsivity, enhanced reward sensitivity, and increased susceptibility toward drugs of abuse (Spear, 2000; Casey et al., 2008; Friemel et al., 2010). The molecular mechanisms that trigger adolescent behavior are unknown. This is alarming when considering that adolescents appear to be prone to suboptimal decisions that may lead to unintentional injuries and/or death (Eaton et al., 2010) and are specifically vulnerable to the emergence of psychiatric disorders (Paus et al., 2008). Understanding the molecular underpinnings of adolescent behavior is therefore critical for understanding the origin of psychopathology.

One molecular candidate system that may be involved in mediating adolescent behavior is the endocannabinoid (eCB) system. The role of eCBs as retrograde messengers to suppress both excitatory and inhibitory transmission is well established. Therefore, the eCB system is considered a ubiquitous regulator of synaptic transmission in the brain that mediates numerous forms of plasticity (Kano et al., 2009; Castillo et al., 2012). Enhanced eCB signaling has been reported to occur during adolescent brain development. In particular, cannabinoid type- 1 receptor (CB1R) expression increases during postnatal development, with peak levels being reached around mid-adolescence in rats (Rodríguez de Fonseca et al., 1993; Schneider, 2008; Klugmann et al., 2011). Accordingly, cannabinoid pharmacology exerts stronger effects in adolescent than adult animals (Schneider et al., 2008; Schneider, 2008; Cass et al., 2014), also providing an explanation of augmented cannabis abuse during adolescence (Schneider, 2008). Because the eCB system represents a crucial mediator of various processes of neuroplasticity, the transient boost in $\mathrm{eCB}$ signaling during adolescence may provide increased plasticity and behavioral flexibility required specifically during this developmental stage. We therefore hypothesized that enhanced CB1R signaling is a mediator of adolescent behavior. Enhanced CB1R signaling may theoretically be obtained by a gain of function of the receptor, but an appropriate genetic animal model does not exist. We also do not have any in silico information on putative

Received May 20, 2015; revised Sept. 1, 2015; accepted Sept. 4, 2015.

Author contributions: M. Schneider, F.M.L., M. Schreckenberger, B.L., P.H.R., 0.J.M., and R.S. designed research; M. Schneider, F.K., D.L.L., C.M.F., O.L., D.P.H., F.S., K.M., C.S., and I.M. performed research; M. Schneider, F.K., D.L.L., C.M.F., D.P.H., K.M., C.S., I.M., B.L., and P.H.R. analyzed data; M. Schneider, B.L., O.J.M., and R.S. wrote the paper.

This work was supported by the Bundesministerium für Bildung und Forschung (e:Med; FKZ: $01 Z X 1311 A^{36}$ to R.S.), Deutsche Forschungsgemeinschaft (SCHN 958/3-1 to M.S., FOR926 SCHN 958/4-1 SP9 to M.S., central project SP3 to B.L. and K.M., and KF0256 Project AP1 to R.S. and M. Schneider), the MWK in Baden-Württemberg (R.S.), the Focus Program Translational Neuroscience of the Johannes Gutenberg University Mainz (I.M.), the National Institutes of Health (Grants R01 DA003934 and K05 DA021358 to P.H.R.), and the Deutsche Forschungsgemeinschaft (Graduate School Grant GRK1044 to F.S.). 0.J.M. acknowledges the support of INSERM and ANR Samenta Cannado. We thank Sabrina Koch, Christian Gluch, and Claudia Schäfer for excellent technical assistance; Reinhard Sedlmeier and Cornelius Pawlak for help and advice with the MT rat line; and Matthias Klugmann and Bernhard Höfle for invaluable scientific advice and their comments during the preparation of the manuscript.

The authors declare no competing financial interests.

Correspondence should be addressed to Dr. Miriam Schneider, Research Group Developmental Neuropsychopharmacology, Institute of Psychopharmacology, Central Institute of Mental Health, Medical Faculty Mannheim, Heidelberg University, 68159 Mannheim, Germany. E-mail: miriam.schneider@zi-mannheim.de.

DOI:10.1523/JNEUROSCI.1937-15.2015

Copyright $\odot 2015$ the authors $\quad 0270-6474 / 15 / 3513976-14 \$ 15.00 / 0$ point mutations in the Cnr1 gene, which encodes for the CB1R that potentially could result in a gain of function of the receptor.

To induce a gain of function of the CB1R, we performed an $N$-ethyl-N-nitrosourea (ENU)-driven, target-selected mutagenesis screen in the rat (van Boxtel et al., 2011). Point mutations in genes of interest can be introduced rapidly by the mutagen ENU (van Boxtel and Cuppen, 2011), which can be combined with a priori target selection (van Boxtel et al., 2011). We preselected a number of eCB-related genes, including $\mathrm{Cnrl}$, and performed an ENU-driven, target-selected mutagenesis screen. In this screen, we identified a point mutation in exon 2 of $C n r l$, which induces an amino acid exchange from phenylalanine to leucine (F238L). We then performed in silico modeling on the encoded mutated CB1R and predicted a gain of function for the receptor. Gain of function was further verified by a series of biochemical, electrophysiological, and pharmacological studies. We then used this novel genetic rat model ( $\mathrm{Cnr} 1^{\mathrm{F} 238 \mathrm{~L}}$ mutants) to assess the role of CB1R signaling in adolescent behavior. In particular, immaturities in adolescent reward processing are thought to promote riskier or suboptimal choices (Casey et al., 2008). It has been shown recently that reward-evoked neural activity differs as a function of age and regions that are not traditionally associated with affective processing in adults, such as the dorsal striatum, may act as critical mediators for reward processing and psychiatric vulnerability in adolescents (Simon and Moghaddam, 2015). Notably, CB1R expression is particularly dense in striatal regions (Kano et al., 2009), so we chose the dorsal striatum as main region of interest for the present study.

\section{Materials and Methods}

Subjects

Male adult/adolescent Fischer 344 rats $(n=85)$ (Charles River Laboratories) and $C n r 1^{\text {F238L }}$ mutant and wild-type (MT/WT) littermates ( $n=$ 165 ) were housed in groups of $3-5$ on a $12 \mathrm{~h}$ light/dark schedule (lights on 7:00-19:00). Water and food were provided ad libitum if not indicated otherwise. The body weight did not differ between genotypes. MT/WT rats were tested in adulthood (with exception of reward intake, which was also assessed in adolescent MT/WT rats) and adolescent Fischer rats in mid-adolescence at postnatal day 38 (P38) to P55 (Schneider, 2013). The body weight between MT and WT rats was compared at 3, 5, 8, and 12 months of age and did not differ significantly (data not shown, ANOVA: $\left.F_{(1,33)}=2.2, p=0.16\right)$. All experiments were conducted in accordance with the European Union guidelines on the care and use of laboratory animals and were approved by the local animal care committee (Regierungspräsidium Karlsruhe, Germany).

\section{Generation of $G_{1}$ individuals and breeding of the $\mathrm{Cnr}^{\mathrm{F} 238 L}$ mutant rat line}

A gene-driven identification approach was used for generation of the Cnr1 MT rat line (Grosse et al., 2006; van Boxtel and Cuppen, 2011; van Boxtel et al., 2011). Male Fischer rats $\left(G_{0}\right)$ were injected intraperitoneally with three weekly doses of $65 \mathrm{mg} / \mathrm{kg}$ ENU (Serva) at Ingenium Pharmaceuticals. ENU-treated $G_{0}$ animals were mated with WT Fischer females and the offspring $\left(G_{1}\right)$ was screened for mutations in the Cnrl gene by temperature gradient capillary electrophoresis ( $\mathrm{Li}$ et al., 2002; Grosse et al., 2006). One missense mutation in exon 2 of the Cnrl gene (F238L) was detected in a male founder rat. The male was mated to female Fischer rats and $G_{2}$ animals were then transferred to the Central Institute of Mental Health in Mannheim (Germany). Animals were backcrossed to WT Fischer rats for 10 generations to avoid potential ENU-driven bystander mutations (van Boxtel and Cuppen, 2011).

\section{Computer model}

Our previously published human WT CB1R model was used as a starting point (Anavi-Goffer et al., 2007). This model contains a truncated $\mathrm{N}$ terminus (last 18 residues were retained) and truncated $\mathrm{C}$ terminus [truncated after G(428)]. This initial hCB1R model was equilibrated in a 
fully hydrated 1-palmitoyl-2-oleoylphosphatidylcholine (POPC) lipid bilayer, followed by $40 \mathrm{~ns}$ of NPAT molecular dynamics simulations at $310 \mathrm{~K}$. The CB1R was then extracted from the simulation cell. The human WT CB1R model was converted to a rat WT model via mutation of the human sequence. These mutations included $\mathrm{I}(106) \mathrm{M}$ and $\mathrm{V}(111) \mathrm{I}$ in the $\mathrm{N}$ terminus, $\mathrm{E}(259) \mathrm{K}$ and $\mathrm{H}(271) \mathrm{L}$ in the second extracellular loop, and $\mathrm{I} 2.62(176) \mathrm{V}$, and R3.22(187) P within the transmembrane helix region. The rat CB1R mutant was generated from the WT rat CB1R via mutation at residue position 4.46 (F4.46L). All mutations were produced using the CHARMM modeling package (MacKerell et al., 1998). The initial rat WT CB1R model was embedded and equilibrated in a fully hydrated POPC lipid bilayer, followed by 40 ns of NPAT molecular dynamics simulations at $310 \mathrm{~K}$. The system contained $240 \mathrm{POPC}$ molecules, 19,485 water molecules, the CB1R (rat WT or rat F4.46L mutant), and 12 chloride ions, the latter of which were added to achieve charge neutrality. An identical procedure was performed to generate the model of the F4.46L mutant in POPC.

Molecular dynamics simulations. The NAMD2 (Phillips et al., 2005) molecular simulation package, along with the CHARMM27 parameter set (MacKerell et al., 1998; Feller and MacKerell, 2000), were used for all molecular energy minimizations and dynamics calculations using a TIP3P water model. Particle Mesh Ewald (PME) was used for the nonbonded interactions using a $10.0 \AA$ real-space cutoff for the short-range electrostatics and a switching function between $10.0 \AA$ and $11.5 \AA$ for the Van der Waals terms. A cutoff of $13.0 \AA$ was used for the neighbor list generation, which was updated every 20 steps. A PME grid size of $90 \times$ $90 \times 128 \AA$ was used for the long-range electrostatic contribution. The following series of energy minimizations were performed to relax the system with respect to the mutated sidechains. First, with all atoms frozen (except the mutated side chains), a short minimization was performed. This was followed by three subsequent minimizations in which: (1) the mutated sidechains and any residue within $5.0 \AA$ were allowed to relax, (2) only the heavy atoms of the protein were fixed, and (3) only the protein backbone atoms were fixed. These minimizations were run for 5000 steps and the entire system was minimized for 20,000 steps. The purpose of these initial minimizations was to gently remove any clashes that resulted from the addition of atoms via the mutations. Each system (rat WT CB1R or rat F4.46L CB1R) was then warmed slowly in $10 \mathrm{~K}$ increments to $310 \mathrm{~K}$ at 20 ps per increment. The calculations were performed at constant volume (NVT ensemble). For Langevin coupling of the heavy atoms to a heat bath, a damping constant of $10 \mathrm{ps}^{-1}$ was used (Bhandarkar et al., 2003). During this heating phase, the heavy atoms of the protein were restrained using a harmonic force $\left(k=0.5 \mathrm{kcal} / \mathrm{mol} \AA^{2}\right)$. After this warming, the restraints were released in $100.5 \mathrm{~ns}$ increments using MD in the NVT ensemble at $310 \mathrm{~K}$. For each subsequent increment, the force constant was reduced by a factor of 10 . Production runs were performed to $300 \mathrm{~ns}$ in the NPAT ensemble using the Nose-Hoover Langevin piston for pressure control and a Langevin bath for temperature control (with a $2 \mathrm{ps}^{-1}$ damping coefficient). A second, replicated trajectory was also performed for both systems in which the velocities were resampled using a Boltzman distribution and the production run was repeated.

Analysis of molecular dynamics trajectories. Trajectory analyses were performed with the VMD (Humphrey et al., 1996) package and associated plug-ins and with additional analysis scripts developed in-house. For the 300 ns molecular dynamics runs, the root mean square deviation from the initial structure was calculated using the VMD RMSD trajectory tool. Root mean square fluctuations were calculated with the RMSF tool available in VMD (Humphrey et al., 1996).

\section{$\left[{ }^{35}\right.$ S] GTP $\gamma$ S analysis}

Agonist-stimulated $\left[{ }^{35} \mathrm{~S}\right] \mathrm{GTP} \gamma \mathrm{S}$ binding assays were performed on striatal tissue (Steindel et al., 2013). Samples were preincubated for $10 \mathrm{~min}$ at $30^{\circ} \mathrm{C}$ in the presence of $0.004 \mathrm{U} / \mathrm{ml}$ adenosine deaminase (SigmaAldrich). Striatal homogenates were incubated with $0.05 \mathrm{~nm}\left[{ }^{35} \mathrm{~S}\right] \mathrm{GTP} \gamma \mathrm{S}$ $\left(1250 \mathrm{Ci} / \mathrm{mmol}\right.$, PerkinElmer). For dose-response experiments, $10^{-13} \mathrm{M}$ to $10^{-7} \mathrm{M}$ of the CB1R agonist $\mathrm{HU}-210$ in assay buffer ( $50 \mathrm{~mm}$ Tris- $\mathrm{HCl}$, pH 7.4, 3 mm $\mathrm{MgCl}_{2}, 0.2 \mathrm{~mm}$ EGTA, $100 \mathrm{~mm} \mathrm{NaCl}$ ) containing $30 \mu \mathrm{M}$ GDP and $0.5 \%$ fatty-acid-free BSA in a final volume of $0.5 \mathrm{ml}$ were incubated for $60 \mathrm{~min}$ at $30^{\circ} \mathrm{C}$. Specific binding values were generated by subtracting nonspecific binding in presence of $30 \mu \mathrm{M}$ GTP $\gamma \mathrm{S}$ from total binding for each agonist concentration. Bound $\left[{ }^{35} \mathrm{~S}\right] \mathrm{GTP} \gamma \mathrm{S}$ was harvested by vacuum filtration through Whatman GF/B filters with a Brandel Cell Harvester, followed by 3 washing steps $(3 \mathrm{ml}$ of ice-cold $50 \mathrm{~mm}$ Tris-HCl buffer, $\mathrm{pH} 7.4$ ). After overnight incubation of filters in $2.5 \mathrm{ml}$ of scintillation mixture Aquasafe 300 plus (Zinsser Analytic), radioactivity was measured by liquid scintillation counting using Tri-Carb 2800 TR (PerkinElmer).

\section{Electrophysiological studies}

Whole-cell patch-clamp recordings were performed from visualized medium spiny neurons located in the dorsolateral striatum (Kasanetz and Manzoni, 2009; Kasanetz et al., 2010). Glass electrodes (resistance 4-6 $\mathrm{M} \Omega$ ) were filled with $(\mathrm{mm}): 128 \mathrm{~K}+$ Gluconate, $20 \mathrm{NaCl}, 1 \mathrm{MgCl}_{2}, 1$ EGTA, $0.3 \mathrm{CaCl}_{2}, 2 \mathrm{Na}^{2+}$ ATP, $0.3 \mathrm{Na}^{+}$GTP, buffered with 10 HEPES, pH 7.3, osmolarity 290-300 mOsm. To evaluate the access resistance (Ra), a $2 \mathrm{mV}$ hyperpolarizing pulse was applied before each EPSC. Ra was not compensated and cells were rejected if Ra was $>25 \mathrm{M} \Omega$ or changed $>20 \%$ during the experiment. The potential reference of the amplifier was adjusted to zero before breaking into the cell. Data were recorded with Axopatch-1D or Axopatch-200B amplifiers (Molecular Devices), filtered at $1-2 \mathrm{kHz}$, digitized at $10 \mathrm{kHz}$ on a DigiData $1332 \mathrm{~A}$ interface (Molecular Devices), and collected on a PC using Clampex (version 9.2 or 10). Analysis was performed using Clampfit (version 9.2 or 10; Molecular Devices). For recording evoked and spontaneous EPSCs (sEP$\mathrm{SCs}$ ), cells were voltage clamped at $-70 \mathrm{mV}$. For assessing paired-pulse facilitation (PPF), synaptic responses to two consecutive stimuli were delivered at different frequencies $(5-40 \mathrm{~Hz})$. The PPF was computed as the ratio between the amplitudes of the second EPSC over the first EPSC. sEPSCs were saved with Axoscope 10 (Molecular Devices) and were detected using a template of sEPSCs generated from averaging several typical synaptic events with Clampfit 10 (Molecular Devices). The template was slid along the data trace one point at a time. At each position, this template was optimally scaled and offset to fit the data. A lower amplitude threshold of $6 \mathrm{pA}$ was applied, equivalent to 2.5 times the SD of baseline noise. For field EPSPs (fEPSPs), extracellular recording electrodes were filled with ACSF. To evoke synaptic currents, electrical stimuli (100-200 $\mu$ s duration) were delivered at $0.1 \mathrm{~Hz}$ with a glass electrode filled with ACSF and placed at a distance $>150 \mu \mathrm{m}$ from the recording electrode.

Slice preparation. Adult and adolescent (P40-P43) rats were deeply anesthetized with halotane and transcardially perfused with a sucrosebased physiological solution at $4^{\circ} \mathrm{C}$ containing the following (in mM): 87 $\mathrm{NaCl}, 75$ sucrose, 25 glucose, $5 \mathrm{KCl}, 21 \mathrm{MgCl}_{2}, 0.5 \mathrm{CaCl}_{2}$, and 1.25 $\left.\mathrm{NaH}_{2} \mathrm{PO}_{4}\right)$. The brain was removed and sliced $(300 \mu \mathrm{m})$ in the coronal plane while maintained in the sucrose-based solution. Immediately after cutting, slices were stored for $40 \mathrm{~min}$ at $32^{\circ} \mathrm{C}$ in a low $\mathrm{Ca}^{2+}$ artificial CSF (ACSF) containing the following (in $\mathrm{mm}$ ): $130 \mathrm{NaCl}, 11$ glucose, $2.5 \mathrm{KCl}$, $2.4 \mathrm{MgCl}_{2}, 1.2 \mathrm{CaCl}_{2}, 23 \mathrm{NaHCO}_{3}$, and $1.2 \mathrm{NaH}_{2} \mathrm{PO}_{4}$ and equilibrated with $95 \% \mathrm{O}_{2} / 5 \% \mathrm{CO}_{2}$. Slices were then stored in low $\mathrm{Ca}^{2+} \mathrm{ACSF}$ at room temperature until recording and then placed in the recording chamber and superfused (1.5-2 $\mathrm{ml} / \mathrm{min}$ ) with ACSF (similar to low $\mathrm{Ca}^{2+}$ ACSF except for $1.2 \mathrm{MgCl}_{2}$ and $\left.2.4 \mathrm{CaCl}_{2}\right)$ containing picrotoxin $(100 \mu \mathrm{M})$ to block GABAA receptors. All experiments were performed at $\sim 30^{\circ} \mathrm{C}$. All drugs were added at the final concentration to the superfusion medium.

\section{Sample collection for Western blot and eCB analysis}

Rats were briefly anesthetized with $\mathrm{CO}_{2}$ and decapitated. Aside from the striatum, we further analyzed expression of components of the eCB system in the hippocampus. For dissection of both regions, $3 \mathrm{~mm}$ of the rostral end of the brain were removed. The adjacent $15 \mathrm{~mm}$ coronal section corresponding to $\sim 2.5$ to $1 \mathrm{~mm}$ from bregma according to Paxinos rat brain atlas was placed on an ice-cold plate. The striatum was bilaterally dissected by a circular section of 3.5-4 mm diameter beneath the corpus callosum, typically yielding $40-50 \mathrm{mg}$ of tissue. A further 3 $\mathrm{mm}$ portion of the brain was removed until the approximate position of $-1.8 \mathrm{~mm}$ from bregma. The complete hippocampus was unwinded and dissected, typically yielding $60-65 \mathrm{mg}$ of tissue per side. 


\section{Western blots}

Immunological staining was conducted for the CB1R, fatty acid amide hydrolase (FAAH), monoacylglycerol lipase (MAGL; Cayman Chemical), and $\beta$-actin (Santa Cruz Biotechnology) as protein standard, as described previously (Schneider et al., 2014). Dissected regions (striatum and hippocampus) were homogenized in $500 \mu \mathrm{l}$ of chilled buffer solution (10 mm TrisHCl, 2 mm EDTA, pH 8.0) containing protease inhibitors (Roche Diagnostics). Samples were mixed with $2 \times$ mercapto/SDS sample buffer (Sigma-Aldrich), denatured at $95^{\circ} \mathrm{C}$ for $5 \mathrm{~min}$ and loaded on precast NuPAGE Novex $4-12 \%$ BisTris Mini-Gels (Life Technologies ). Electrophoresis was performed at $180 \mathrm{~V}$ for $60 \mathrm{~min}$ using MOPS running buffer (Life Technologies ). Proteins were subsequently blotted onto PVDF FL membranes (Millipore) using Towbins buffer and $400 \mathrm{~mA}$ current for $90 \mathrm{~min}$. Membranes were blocked in Odyssey blocking buffer (Li-Cor Biosciences) at room temperature for $1 \mathrm{~h}$. The primary antibody was coincubated with the $\beta$-actin antibody [concentrations: CB1 (1:750), FAAH (1: 1000), MAGL (1:500), and $\beta$-actin (1:2000)]. Primary antibodies were incubated for $24 \mathrm{~h}$. Subsequently, membranes were washed $3 \times$ with $1 \times$ TBS with $0.1 \%$ Tween (TBS-T) and incubated with fluorescent secondary antibody diluted in Odyssey blocking buffer for $1 \mathrm{~h}$ at room temperature. The secondary antibodies were raised either antirabbit (Li-Cor Biosciences) targeting CB1R, FAAH, and MAGL antibodies or anti-goat (Li-Cor Biosciences) targeting $\beta$-actin antibodies and differed in the fluorescent signal wavelength. Both antibodies were coincubated with a dilution of 1:10.000. Membranes were washed $3 \times$ with TBS-T and aqua bidest prior fluorescent scanning (Li-Cor Biosciences). Analysis of band density was done with Image Studio software (Li-Cor Biosciences). The expression levels of CB1R, FAAH, and MAGL were corrected for the $\beta$-actin content. Values were expressed as arbitrary units.

\section{Endocannabinoid measurement}

The two main eCBs, $\mathrm{N}$-arachidonoylethanolamide (AEA) and 2-arachidonoylglycerol (2-AG), were extracted as described previously (Fegley et al., 2005) with methanol-chloroform $(2 / 1 \mathrm{v} / \mathrm{v})$ and fractionated by open-bed silica gel chromatography. The organic phase was concentrated before analysis. Endocannabinoids were measured by isotopedilution liquid chromatography/tandem mass spectrometry performed with an Agilent 1200 high-performance liquid chromatography (HPLC) system coupled to an API 5000 triple quadrupole mass spectrometer (AB Sciex) operating in positive electrospray ionization mode. Fragmented ions of AEA and 2-AG were quantified in the multiple reaction monitoring mode.

\section{CB1R PET}

Acquisition of the PET data after administration of the CB1R ligand $\left[{ }^{18} \mathrm{~F}\right] \mathrm{MK}-9470$ was conducted using a Focus 120 microPET scanner (Siemens/CTI). The detectors were composed of lutetium oxyorthosilicate detectors for coincidence detection (timing window: $6 \mathrm{~ns}$; size: $1.5 \times$ $\left.1.5 \times 10 \mathrm{~mm}^{3}\right)$. A resolution of $\leq 1.4 \mathrm{~mm}$ was achieved at the center of the field of view. Before the emission scan, a $10 \mathrm{~min}{ }^{57} \mathrm{Co}$ transmission scan was performed. The acquisition time was $60 \mathrm{~min}$, resulting in list mode data that were sorted into $1 \times 2400 \mathrm{~s}$ and a $1 \times 1200 \mathrm{~s}$ sinograms. Reconstruction was undertaken by filtered back projection (ramp filter, cutoff $=0.5$ ) into 95 slices of $0.80 \mathrm{~mm}$ thickness ( pixel size: $0.87 \times 0.87$ $\mathrm{mm}^{2}$ ) and a matrix of $128 \times 128$ pixels. Correction of the data was applied for dead time, randoms, attenuation, and scatter. Regional mean radioactivity values and $\left[{ }^{18} \mathrm{~F}\right] \mathrm{MK}-9470$ uptake ratios were calculated (Miederer et al., 2013; mean uptake of the target region/mean uptake of the whole brain). Radiolabeling was conducted by reaction with $\left[{ }^{18} \mathrm{~F}\right]$ fluoroethyltosylate (PETNET), whereby the phenolic group of the precursor ([N-[(1S,2S)-2-(3-cyanophenyl)-3-(4-hydroxyphenyl)-1-meth ylpropyl]-2-methyl-2-[(5-methylpyridin-2-yl)oxy]propanamide) was deprotonated with cesium carbonate (Sigm-Aldrich) in dimethylformamide (Fluka). The production time, including HPLC and C18 cartridge purification, was $30 \mathrm{~min}$, which yielded the CB1R ligand $\left[{ }^{18} \mathrm{~F}\right] \mathrm{MK}-9470$. The positioning of the rats in the scanner was head first supine and they received $2-2.5 \%$ isoflurane vaporized in $100 \% \mathrm{O}_{2}$. To enable administration of the ligand, a peripheral venous catheter was inserted into the tail vein.

A 60 min summed PET image was calculated and coregistered by rigid-body transformation to an MR T2 rat template that was provided by the PMOD software package (version 3.12). The obtained transformation parameters were applied to the PET data from minutes 40-60. Volumes of interest in the striatum, hippocampus, and whole brain were selected from the template and projected onto the PET image.

\section{Behavioral testing and pharmacological experiments}

Behavioral testing took place during the light phase, except for recording of social play behavior. If not indicated otherwise, the behavioral performance was videotaped and rated offline by a trained observer blinded to genotype.

\section{Experimental design and age of testing}

Six cohorts were used for the behavioral experiments in WT and MT rats. Animals were tested at an age between 4 and 8 months, except for cohort 6 , which was tested during adolescence. The first cohort (MT, $n=13$, WT $n=10)$ was tested in the open-field test, elevated plus maze (EPM) test, light/dark emergence test (EMT), novelty preference test, novel object exploration test, delay discounting test, limited access food reward intake test, and progressive ratio (PR) test (with a break of $3-5 \mathrm{~d}$ between each test session) and some of these animals were videotaped for social play behavior (MT, $n=11$; WT, $n=9$ ). One WT rat had to be removed from further analysis during delay discounting testing because it did not achieve the initial criterion. A second cohort (MT, $n=6$; WT, $n=8)$ was used for cocaine sensitization and CPP. Cohorts 3 and 4 were tested for the dose-response effects of cocaine (MT, $n=7$; WT, $n=12$ ) and the inhibitory effects of SR 141716 on palatable food intake (MT, $n=10$; WT, $n=11$ ). Cohort 5 (MT, $n=12$; WT, $n=6$ ) was used in the predator odor risk-taking (PORT) task and a final cohort (Cohort 6) was used to assess reward intake in adolescence (MT/WT, $n=7$ ).

Three cohorts were used for behavioral testing in adolescent/adult Fischer animals. Adolescent rats were tested between P38 and P55 (Schneider, 2013) and adult animals were tested at an age of 4-6 months. The first cohort $(n=12)$ was used for behavioral testing. Due to the restricted time window of adolescence (Schneider, 2013) and the already existing body of literature describing an adolescent phenotype in rodents (for review, see Spear, 2000), only a selection of short behavioral tests previously performed in MT animals was repeated in adolescent and adult Fischer rats. Cohorts 2 and 3 were used to examine the dose-response effects of cocaine (adolescent, $n=12$; adult, $n=10$ ) and the inhibitory effects of SR141716 on food intake (adolescent, $n=8$; adult, $n=9$ ).

\section{Risk-taking behavior}

Open-field, EPM, and EMT tests were performed as described previously (Goepfrich et al., 2013). Locomotor activity was measured in an open field $(50 \times 50 \times 45 \mathrm{~cm})$ made of dark PVC. Distance traveled (in centimeters) was digitally recorded for $30 \mathrm{~min}$ at a light intensity of $150 \mathrm{~lx}$ (and $3 \mathrm{~d}$ later again at $50 \mathrm{~lx}$ ) by the observation program Viewer $^{2}$ (Biobserve). Performance in the EPM was recorded for 5 min (open arm illumination of $75 \mathrm{~lx}$ ). The following behaviors were analyzed: number of entries into open or closed arms and time spent in open and closed arms (in seconds). Percentage of open arm entries and percentage of time spent in open arms were calculated. Light/dark EMT testing took place for $5 \mathrm{~min}$ in a 2 compartment box (illumination: $80 \mathrm{~lx}$ ). Subsequent manual video analysis scored the emergence latency (in seconds) and the duration of time spent in the light compartment (in seconds).

Risk-based decision making was assessed by the PORT task (Dent et al., 2014). Testing consisted of initial food reward (casein pellet; Bio Serve Dustless Precision Pellets; Bilaney) collection in various contexts and a final testing phase in the presence of a neutral odor (unscented bedding) or predator odors (urine-scented bedding: coyote/ mountain lion).

Apparatus. The PORT test apparatus consisted of a dark gray PVC arena divided into three compartments arranged in a row such that the middle compartment could be entered from both end compart- 
a

C

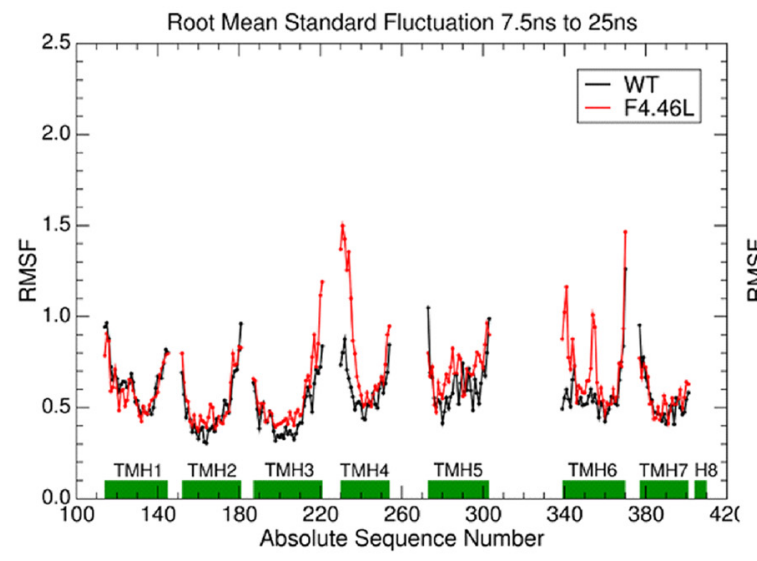

b

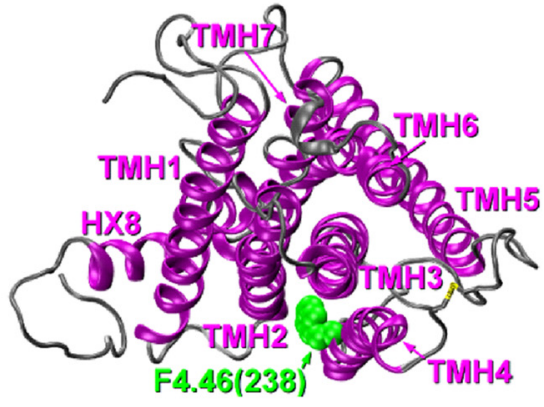

d

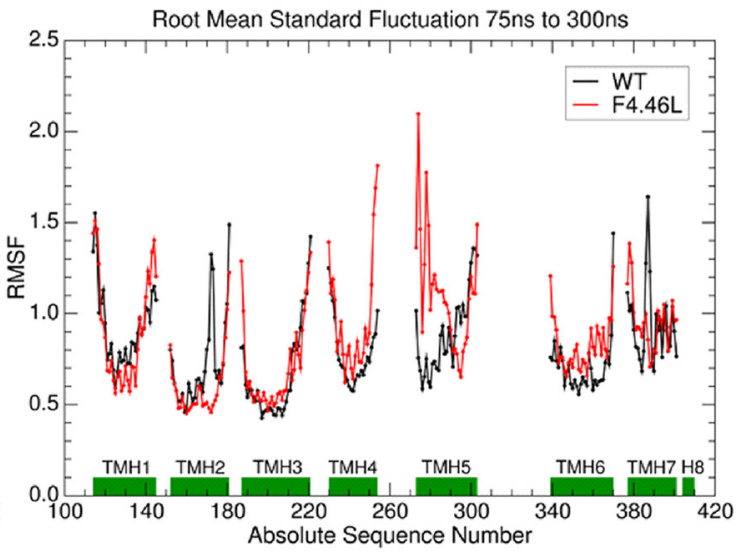

Figure 1. Location of residue 4.46(238) in the CB1R $(\boldsymbol{a}, \boldsymbol{b})$ and molecular dynamics results for wild-type (WT) and mutant (MT) CB1R (c, $\boldsymbol{d})$. In $\boldsymbol{a}$, the transmembrane helix (TMH) bundle is shown in a side view looking from the lipid bilayer toward TMH2/3/4. Here, it is clear that 4.46(238) (green) is located on the lipid face of TMH4, one turn below the highly conserved class A G-protein-coupled receptor residue, W4.50 (orange). In $\boldsymbol{b}$, the CB1R is shown in an extracellular view, with the location of residue 4.46(238) highlighted in green. Here, it is clear that residue 4.46(238) faces the TMH2-3-4 outside interface. c presents a plot of root mean square fluctuations (RMSF) for the transmembrane portion of rat WT CB1R(black) and the F238L mutant (red) versus residue number for the period before W6.48 undergoes the $\chi_{1} \mathrm{~g}+\rightarrow$ trans conformational change (7.5-25 ns portion of MD trajectory). The green bars identify the residue spans for each TMH. The RMSF values for the F238L mutant (red) are larger than WT (black) in the following regions: the intracellular (IC) ends of TMH3/TMH4 (the IC-2 loop), the IC end of TMH6 (IC-3 loop), as well as the TM portion of TMH6 itself. Similar results were obtained for the second trajectory. This increase in RMSF is an indicator of increased flexibility of these regions in the MT receptor compared with WT. $\boldsymbol{d}$ presents a plot of RMSF for the transmembrane portion of rat WT CB1R (black) and the F238L MT (red) versus residue number for the period after W6.48 returns to a $g+\chi_{1}(75-300$ ns portion of MD trajectory). The green bars identify the residue spans for each transmembrane helix. The EC ends of TMH4 and TMH5 (ends of EC-2 loop) of the MT undergoes the largest fluctuation, which is consistent with previous studies showing EC-2 loop movement during GPCR activation (Ahn et al., 2009; Ahuja et al., 2009; Bertalovitz et al., 2010). Similar results were obtained for the second trajectory.

ments. The compartments were separated by a dividing wall with a $12-\mathrm{cm}$-wide opening that enabled the test subjects to move freely between the compartments. The first compartment was small and served as starting box $(20 \times 50 \times 45 \mathrm{~cm})$, the two following compartments were equal in size $(35 \times 50 \times 45 \mathrm{~cm})$. The second compartment could be filled with scented/unscented bedding and, in the third (end) compartment, the food reward was provided in a small Petri dish attached to the floor. The box was thoroughly cleaned with $70 \%$ alcohol between sessions.

Testing procedure. First, animals were habituated to the casein pellets in their home cage for 2 consecutive days. After habituation, the latency to collect a pellet was assessed in various contexts with different degrees of familiarization. First, latency to collect the food reward was measured in the home cage. Animals were then habituated for $10 \mathrm{~min}$ to the test apparatus and, $24 \mathrm{~h}$ later, the latency to collect reward in the apparatus was recorded. Therefore, animals were placed in the start chamber and were required to cross the middle chamber to collect the reward in the end compartment. Latency until the pellet was collected and eating was initiated was recorded. This was repeated after $5 \mathrm{~d}$ of habituation to the test apparatus and the availability of casein pellets. After apparatus habituation, the animals were then habituated to the presence of bedding material (standard rat bedding) in the middle compartment of the box.
The final testing phase consisted of 3 testing days with a $48 \mathrm{~h}$ break between test sessions. The middle compartment of the apparatus was then filled with $600 \mathrm{ml}$ of bedding (either unscented or scented with predator urine) that was distributed evenly over the entire floor of the compartment and had to be crossed by the animals to obtain the food reward. All subjects had to complete three successive trials per test session with various odor conditions (neutral, mountain lion, and coyote). A trial ended when the rat initiated eating of the pellet, with a maximum trial duration of $10 \mathrm{~min}$. From the latency of all three trials, the mean was calculated per session/per animal. Fresh scented bedding was used for each animal.

Predator odors. Unscented standard animal bedding (corn cob bedding) was used as a neutral cue in the control condition. In the risk-taking sessions, two predator odors were applied. We used coyote and mountain lion urine (Maine Outdoor Solutions). Thirty milliliters of urine was pipetted onto 10 pieces of filter paper $\left(10 \mathrm{~cm}^{2}\right)$, which were then placed in a bag containing $6 \mathrm{~L}$ of bedding material. Therefore, every $600 \mathrm{ml}$ of scented bedding placed in the middle chamber of the apparatus was equivalent to $3 \mathrm{ml}$ of predator urine. All odor mixtures were made $1 \mathrm{~d}$ before use and kept in sealed bags in a room separate from the holding or test rooms. 
a

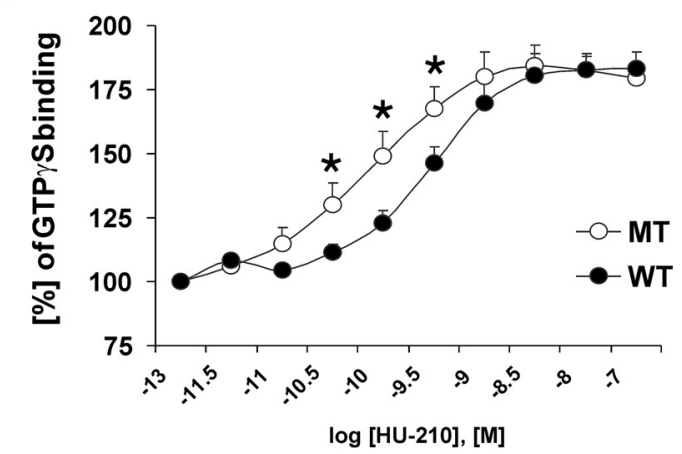

C $\mathbf{W T}$
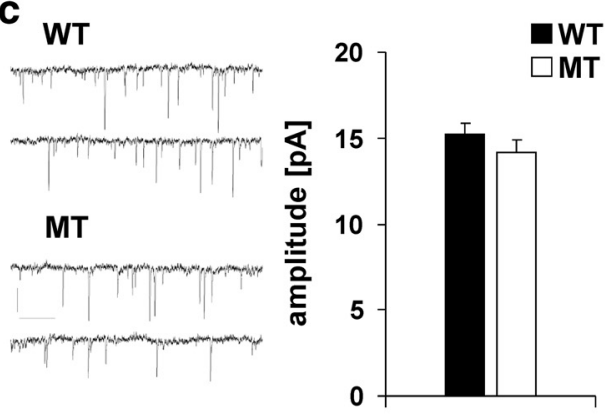

b

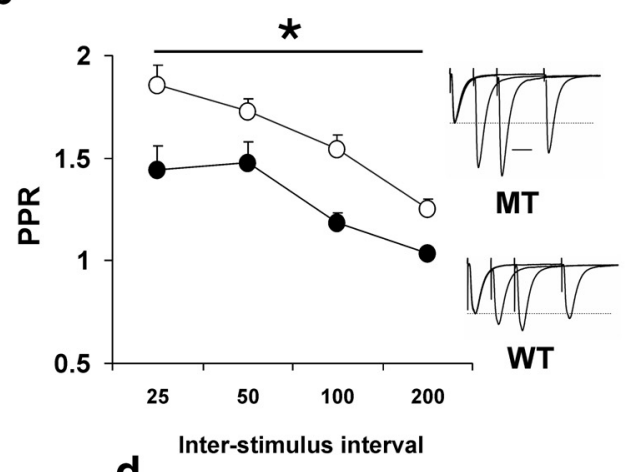

d
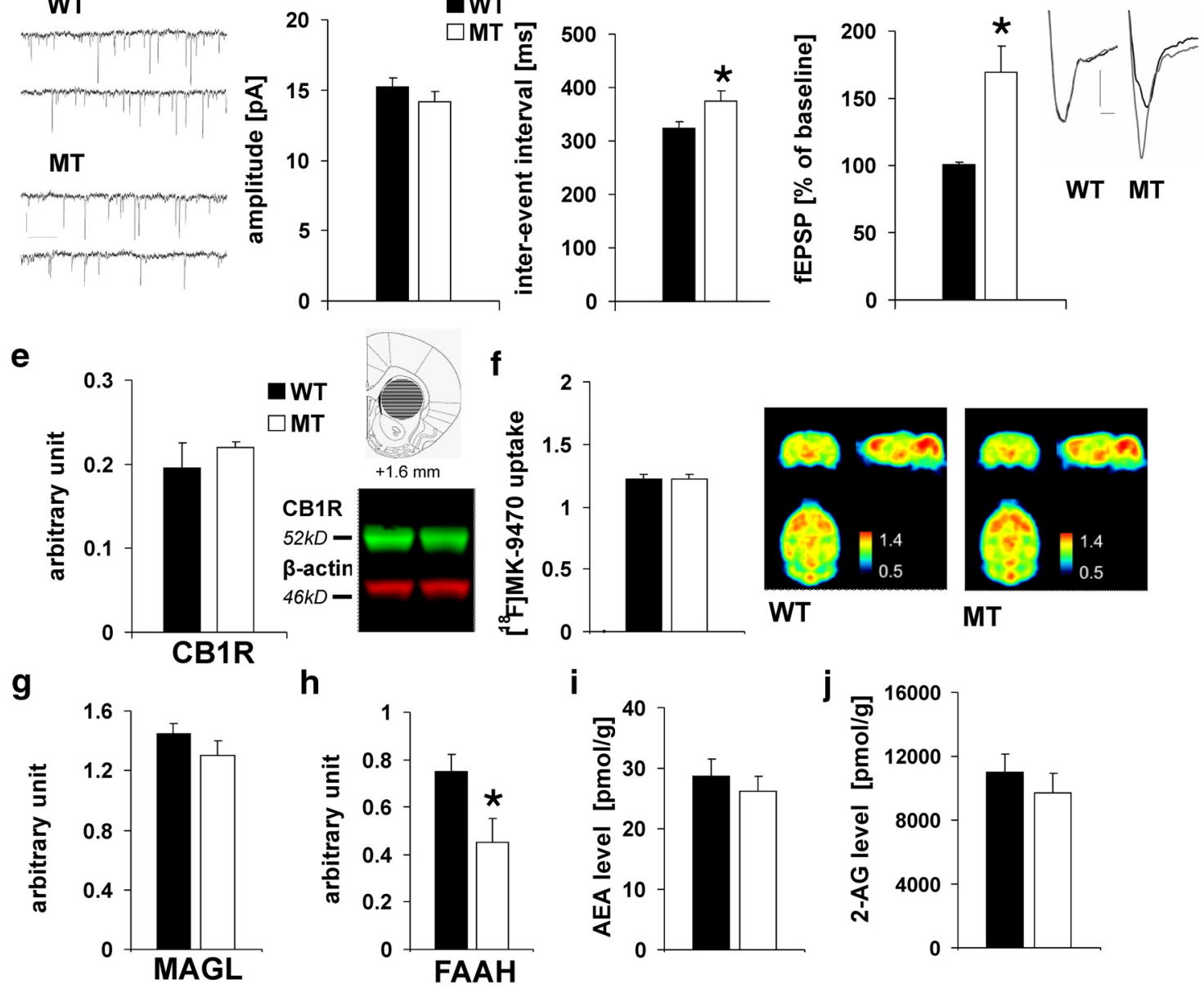

Figure 2. Functional characterization and expression of the mutated CB1R and other components of the eCB system in the striatum of $C n r 1$ mutant (MT) and WT rats. $\boldsymbol{a}, \boldsymbol{b}$, Cannabinoid-induced $\left[{ }^{35} \mathrm{~S}\right] \mathrm{GTP} \gamma \mathrm{S}$ binding $\left(\boldsymbol{a}\right.$; interaction effect: $\left.F_{(9,54)}=2.1, p=0.048\right)$, as well as PPR $\left(\boldsymbol{b}\right.$; genotype effect: $\left.F_{(1,69)}=13.6, p=0.001\right)$ were significantly higher in MT animals compared with WT littermates. Representative traces for PPR: EPSC amplitudes are normalized to the peak of the first EPSC. In each example, there are three trials superposed (for three different interstimulus intervals). Scale bar, $20 \mathrm{~ms}$. No differences could be observed for sEPSC amplitude ( $p=0.27$ ), but the interevent interval was enhanced ( $p=0.034)$ in MT rats. Representative traces for sEPSCs are shown. There are 7 consecutive seconds for each condition (two rows per each). Scale bar, $10 \mathrm{pA} ; 500 \mathrm{~ms}$ (c). Effects of the CB1R antagonist/inverse agonist SR141716 (SR, $2 \mu \mathrm{m}$ ) on field EPSP (fEPSP) were significantly stronger $(p=0.01)$ in MT rats. Representative traces of field EPSPs recorded before (black) and after (gray) application of SR141716. Scale bar, $0.1 \mathrm{mV} ; 2 \mathrm{~ms}$ (d). CB1R expression did not differ between genotypes. No significant differences could be detected between MT animals and WT controls for protein levels (e) (Western blot analysis) $(p=0.50)$ and uptake of the CB1R ligand $\left[{ }^{18} \mathrm{~F}\right]$ MK-9470 (assessed in vivo by PET analysis) $(p=0.95)(\boldsymbol{f})$. Protein levels of monoacylglycerol lipase (MAGL) were also unaltered $(p=0.73)(\boldsymbol{g})$, but FAAH levels were significantly lower in MT ( $p=0.043)$ compared with WT rats $(\boldsymbol{h})$. No significant differences between the genotypes could be found for expression of AEA $(p=0.62)(\boldsymbol{i})$ and $2-A G(p=0.58)(\boldsymbol{j})$. All data are indicated as means \pm SEM ( ${ }^{35}$ SIGTP $\gamma$ S: MT/WT $n=4$; PPR: MT $n=12$; WT $n=13$; sEPSC: $n=12$; SR on fEPSP: MT: $n=6$, WT $n=5$; Western blot CB1R: $n=5$; PET analysis: $n=6$; Western blot FAAH, MAGL: $n=5 ;$ AEA, 2-AG: MT: $n=9$, WT $\left.n=14 ;{ }^{*} p \leq 0.05\right)$.

Limited access SCM intake

Sweetened condensed milk (SCM) (Nestle; freshly mixed 1:3 with water) was used as palatable food reward. Intake was measured for 15 min as described in detail previously (Brand et al., 2012; Goepfrich et al., 2013) and calculated as milliliters intake/kilogram body weight.
For assessing the effects of SR141716 on food reward intake, animals were tested twice for SCM intake after intraperitoneal injections of a low dose of SR141716 $(0.3 \mathrm{mg} / \mathrm{kg})$ or vehicle in a withinsubject design. Between the test sessions, animals were left undisturbed for $5 \mathrm{~d}$. 
a

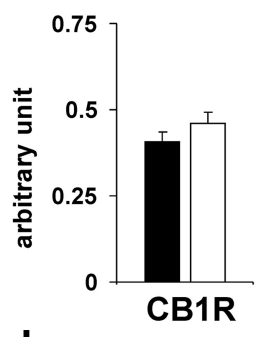

d

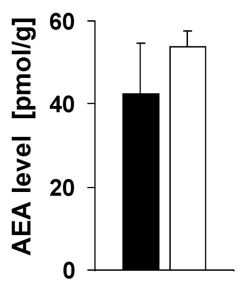

b

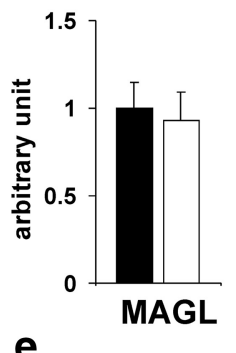

C
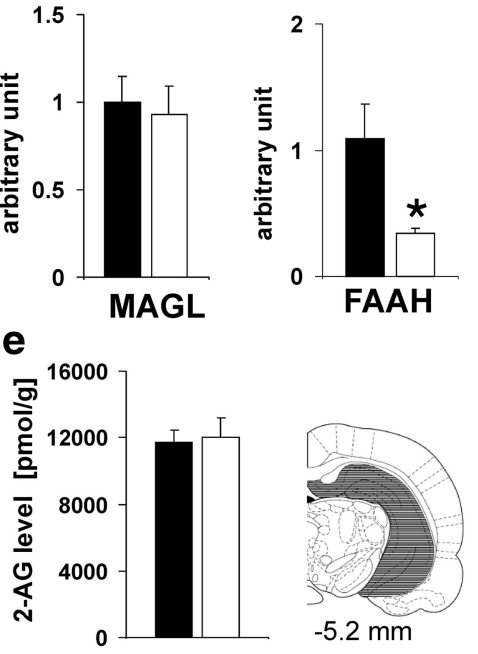

Figure 3. Expression of $C B 1 R$ and other components of the eCB system in the hippocampus. (B1R protein levels in the rat hippocampus did not differ between MT animals and WT controls (a) $(p=0.2)$. Protein levels of MAGL were also unaltered $(\boldsymbol{b})(p=0.8)$. As in the striatum, FAAH levels were significantly reduced in MT compared with WT rats $(c)(p=0.03)$. No significant differences between the genotypes could be found for expression of AEA $(\boldsymbol{d})(p=0.32)$ and 2-AG $(\boldsymbol{e})(p=0.85)$. Data are indicated as means \pm SEM (Western blot analysis: CB1R and MAGL $n=5$; FAAH: $\mathrm{MT} n=5$, WT $n=4$; AEA, 2-AG: MT: $n=9$, WT $n=14 ;{ }^{*} p \leq 0.05$ ).

PR test

PR testing was conducted in operant chambers (Med Associates). Rats were trained to lever press for $90 \mu \mathrm{l}$ of SCM in daily sessions of $30 \mathrm{~min}$. Training was performed under continuous reinforcement until a stable baseline was reached ( $>60$ lever presses). During PR testing, the number of lever presses required for reward delivery increased sequentially according to a progression of 2 (PR2). The highest completed PR sequence during the complete 30 min test session was recorded. During testing, animals were maintained on $\sim 95 \%$ of their free-feeding bodyweight.

\section{Delay discounting}

Delay discounting (Adriani et al., 2009) was conducted in operant boxes. During training, lever pressing on the left lever delivered a small reward $(30 \mu \mathrm{l})$, whereas the right lever dispensed the larger reward $(150 \mu \mathrm{l})$. Training continued until animals displayed a stable preference for the right lever $(\sim 80 \%)$ over 3 consecutive days. During the testing phase, a delay was inserted between the lever press and the delivery of the larger reward. The delay remained fixed over the daily session and was increased over the subsequent days $(5,10,15,20,25 \mathrm{~s})$. During the delay, any further presses on this lever were ineffective (no SCM delivery). During testing, animals were maintained on $\sim 95 \%$ of their free-feeding bodyweight.

\section{Social play behavior}

Animals were videotaped in their home cage for $1 \mathrm{~h}$ directly after onset of the dark cycle. The recorded hour was divided into three short intervals (20 min duration) that were prescreened for the occurrence of play to identify intervals with intense play bouts (Schneider et al., 2014). All play bouts recorded were analyzed either in slow motion or by frame-byframe advancement, depending upon the complexity of the sequence and pinning, and attacks were counted.

\section{Behavioral response to cocaine}

Sensitization to cocaine $(10 \mathrm{mg} / \mathrm{kg}$, i.p.) was measured in the open field in sessions of $30 \mathrm{~min}$. First, baseline activity was measured after vehicle injection, followed by daily cocaine injections on the following $5 \mathrm{~d}$. All animals were challenged again with cocaine on day 12 after the first injection. Percentage sensitization was calculated for cocaine injection on days 1,5 , and 12 in relation to baseline activity. Conditioned place preference (CPP) for cocaine was performed using a biased training pro-

cedure (Schneider et al., 2010). Initial place preference for the test compartments was recorded for $15 \mathrm{~min}$. Conditioning included eight alternating training sessions of $30 \mathrm{~min}$ (one session per day), four for cocaine $(10 \mathrm{mg} / \mathrm{kg})$, and four for vehicle. After the last training day, CPP was measured for $15 \mathrm{~min}$. The CPP score was calculated as the difference between the time (in seconds) spent in the cocaine-assigned compartment before and after conditioning. The acute stimulatory effects of different doses of cocaine/vehicle $(5,10,20 \mathrm{mg} / \mathrm{kg})$ on locomotor activity were assessed by a within-subject procedure. Locomotor activity was assessed for 30 min directly after injection every fifth day.

\section{Drugs}

The cannabinoid agonist HU-210 (Tocris Bioscience) was used for $\left[{ }^{35} \mathrm{~S}\right] \mathrm{GTP} \gamma \mathrm{S}$ binding experiments, dissolved in DSMO, and then diluted in assay buffer (50 mm Tris- $\mathrm{HCl}$, pH 7.4, 3 mM $\mathrm{MgCl}_{2}, 0.2$ mM EGTA, 100 $\mathrm{mm} \mathrm{NaCl}$ ). The CB1R antagonist/inverse agonist SR141716 (SR, generously provided by the National Institute on Drug Abuse) was dissolved in ethanol and Tween 80 and diluted with saline (1:1:18). A dose of $2 \mu \mathrm{M} \mathrm{SR}$ was used for the electrophysiological study and a dose of $0.3 \mathrm{mg} / \mathrm{kg}$ was used for the pharmacological experiments. SR was injected $30 \mathrm{~min}$ before testing with an injection volume of $1 \mathrm{ml} / \mathrm{kg}$. Cocaine (Sigma-Aldrich) was dissolved freshly in saline and injected immediately before testing with an injection volume of $1 \mathrm{ml} / \mathrm{kg}$. For behavioral sensitization and $\mathrm{CPP}$, a dose of $10 \mathrm{mg} / \mathrm{kg}$ was used. For the dose-response effects on locomotor activity, doses of 5, 10, and $20 \mathrm{mg} / \mathrm{kg}$ were administered.

\section{Statistical analysis}

Differences between MT and WT rats and between adolescent and adult animals were analyzed by Student's $t$ tests, with exception for: $\left[{ }^{35} \mathrm{~S}\right] \mathrm{GTP} \gamma \mathrm{S}$ binding, paired-pulse ratio (PPR), PORT, delay discounting test, cocaine sensitization, cocaine dose-response curve, and the effects of SR141716 on SCM intake. These measures were all analyzed by repeated-measures two-way ANOVA with the Student-Neuman-Keuls test as post hoc analysis. All data are expressed as means \pm SEM. The level of statistical significance was defined as $p<0.05$.

\section{Results}

The missense mutation in exon 2 of $C n r 1$ induced an amino acid exchange from phenylalanine to leucine (F238L) and falls into the fourth transmembrane (TMH4) region of the CB1R protein at position 4.46. The amino acid residue 4.46(238), which corresponds to the F238L mutation, is located on the lipid face of TMH4 facing the TMH2-3-4 outside interface (Fig. 1). In silico modeling of the mutated CB1R indicated a TMH bundle with increased flexibility in key regions associated with receptor activation, making the mutant protein a more labile receptor than the WT CB1R. The aromatic interaction between F3.36 and W6.48 was identified as the binding pocket toggle switch for CB1R (McAllister et al., 2004). These residues have been proposed to undergo a conformational change (W6.48 $\chi_{1} g+\rightarrow$ trans and F3.36 transition $\chi_{1}$ trans $\rightarrow g+$ ) as CB1R activates. Two separate $300 \mathrm{~ns}$ molecular dynamics trajectories were run. In the mutant CB1R, the $\chi_{1}$ of W6.48 changed rotameric state ( $\mathrm{g}+\rightarrow$ trans) in both trajectories. In contrast, in both WT trajectories, the $\chi_{1}$ of W6.48 remained in $\mathrm{g}+$ for the entire $300 \mathrm{~ns}$ (Fig. 1c,d). Given that the change of the rotameric state of W6.48 is part of the toggle switch mechanism for activation (McAllister et al., 2004), these results suggest a larger propensity for the F238L mutant to form the activated form of the receptor, predicting a gain-of-function model of the mutant CB1R.

Gain of function of the receptor was then verified by a series of biochemical and electrophysiological experiments. Striatal $\left[{ }^{35} \mathrm{~S}\right] \mathrm{GTP} \gamma \mathrm{S}$ binding was significantly higher in MT than in WT, indicating a higher activity of the CB1R (Fig. $2 a$; for statistics, see figure legends). The PPR is thought to inversely correlate with the basal probability of neurotransmitter release. Because activation 
a

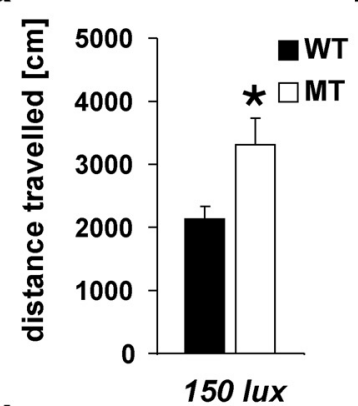

d

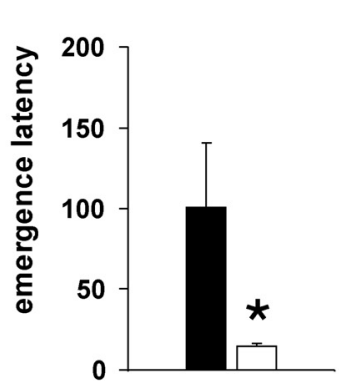

b

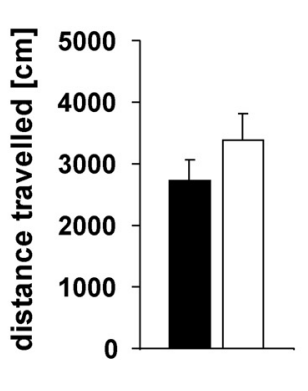

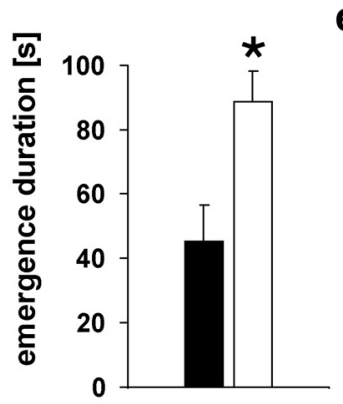

c

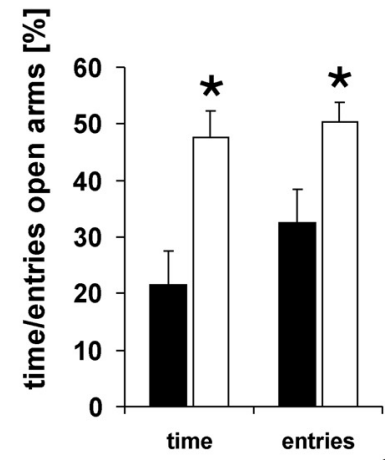

e

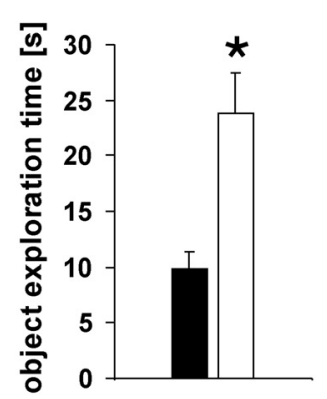

h

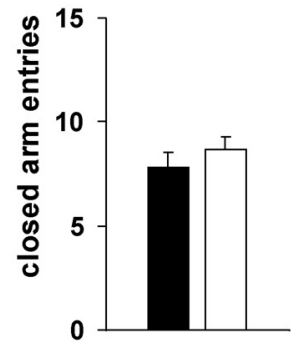

f

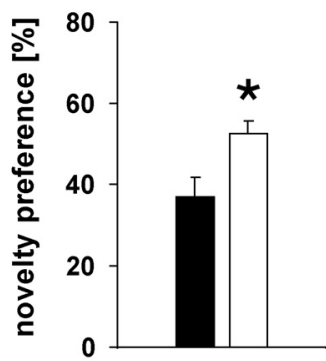

g

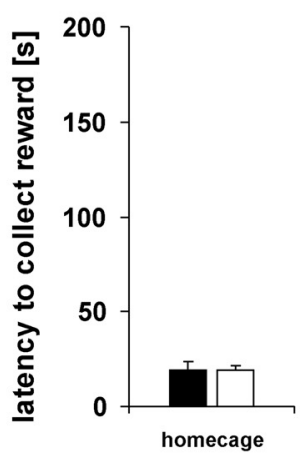

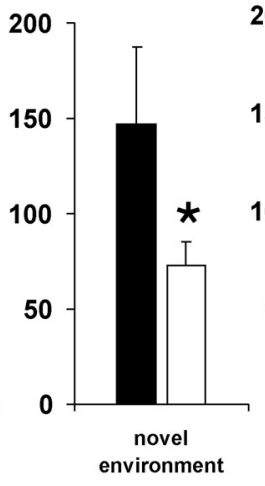

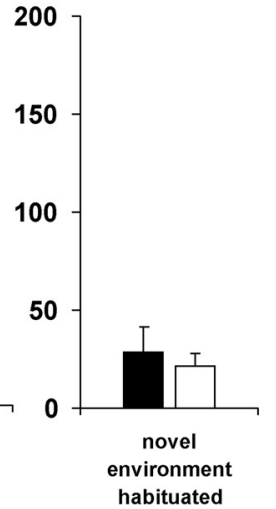

(

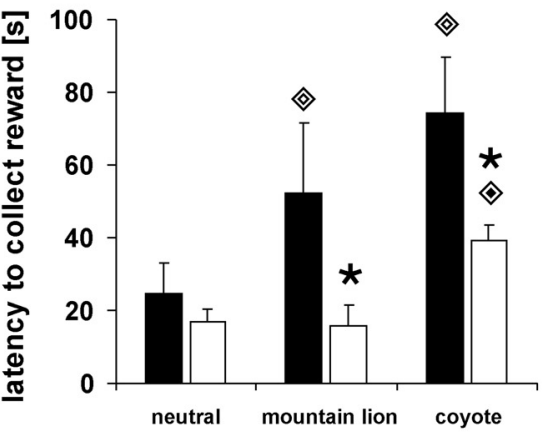

Figure 4. Novelty-seeking and risk-taking behavior of adult Cnr1 MT and WT animals. MT rats showed a significantly higher activity in the open-field test than WT when tested under high-anxiety conditions (unhabituated testing and a high light intensity of $150 \mathrm{~lx} ; p=0.026)(\boldsymbol{a})$. Only a trend for increased activity between the genotypes was observed when animals were retested in the open field under low anxiety conditions $(\boldsymbol{b})(p=0.062$ ). MT rats were found to show increased risk-taking behavior in the EPM (\% time: $p=0.002 ;$ percentage entries: $p=0.011)$ compared with WT (c), although the acitivity level did not differ between the genotypes (closed arm entries: $p=0.38)$. In the light/dark emergence test (d), MT rats showed a decreased emergence latency $(p=0.021)$ and spent more time in the lit compartment $(p=0.008)$ than WT controls. MT also showed higher novelty-seeking during exploration of a novel object $(p=0.005)(\boldsymbol{e})$ and novelty preference testing $(p=0.013)(\boldsymbol{f})$. Risk-based decision making was assessed in a PORT. First, the latency to collect a palatable food reward was assessed in various contexts with different degrees of familiarization $(\boldsymbol{g})$. No genotype differences were found in the latency to collect the pellet within in the home cage $(p=0.98)$, whereas WT rats showed initially a significant higher latency in reward collection in the test apparatus $(p=0.048)$, which was not observable anymore after 5 d of habituation to the test environment $(p=0.41)$. MT and WT rats differed significantly during PORT testing (interaction effect: $\left.F_{(2,32)}=7.72, p=0.002\right)(\boldsymbol{h})$. Presentation of both predator odors increased reward-collection latency significantly in WT (mountain lion: $p<0.001$; coyote: $p<0.001$ ), whereas only the coyote odor affected response latency in MT rats $(p<0.001)$. Latency did not differ between the genotypes in the control condition $(p=0.57)$, but was significantly enhanced in WT compared with MT animals for both predator odors (mountain lion: $p=0.01$; coyote: $p=0.013$ ). Data are indicated as means \pm SEM (open-field, EPM, EMT, novel object exploration, novelty preference: MT $n=13, \mathrm{WT} n=10$; PORT:MT: $n=12$, WT $n=6$; ${ }^{*} p \leq 0.05$ ).

of CB1R inhibits neurotransmitter release, including glutamate, PPR should be enhanced in MT rats. We compared excitatory synaptic responses with 2 consecutive stimuli delivered at different frequencies $(5-40 \mathrm{~Hz})$ and indeed detected an increased PPR in MT rats (Fig. 2b). We then recorded sEPSCs from striatal neurons to assess presynaptic function of the mutated CB1R. No differences were observed for sEPSC amplitude, but the sEPSC interevent interval was significantly enhanced in MT rats (Fig. 2c). Finally, striatal field EPSPs were induced by electrical stimulation of local axons and CB1R function was evaluated with the inverse agonist/antagonist SR141716 (Rimonabant; $2 \mu \mathrm{M}$ ). This treatment had no consequences on fEPSP in WT rats, but induced a strong potentiation of synaptic transmission in MT (Fig. 2d). Altogether, these results showed an altered function in Cnrl MTs with a decreased probability of glutamate release, indicating enhanced presynaptic CB1R signaling.

A gain-of-function mutation in the Cnrl gene might lead to alterations in the entire eCB system. Therefore, we studied the most important components of the eCB system in the striatum and the hippocampus, which show a dense expression of CB1R (Kano et al., 2009). Western blot analysis indicated no differences in striatal CB1R protein levels. This was confirmed in vivo by PET, demonstrating the same level of CB1R-binding sites in MT and WT rats (Fig. 2e,f). No differences were found in protein levels of MAGL (Fig. $2 g$ ), but the AEA-degrading enzyme FAAH was decreased in MT rats (Fig. $2 h$ ). Mass spectrometry was then used to quantify 
a

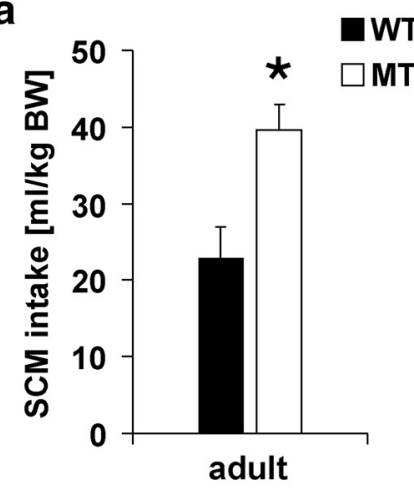

d

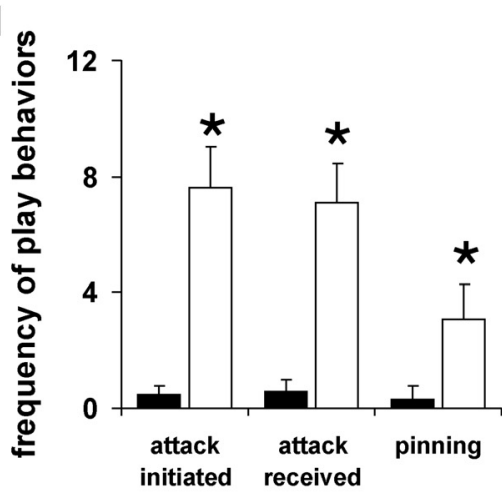

f

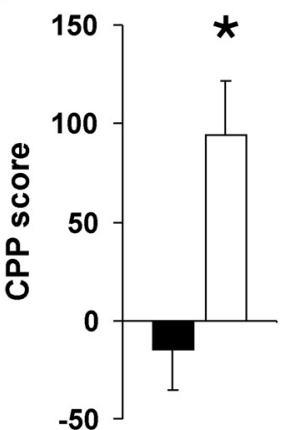

g b

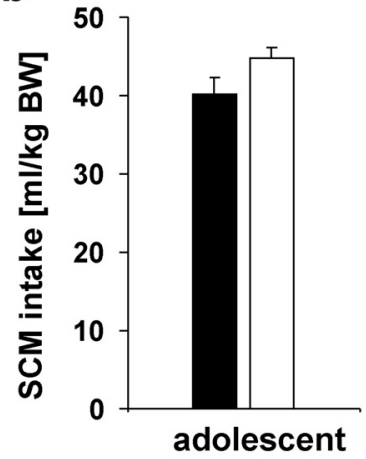

C

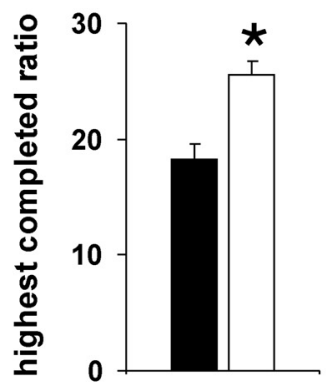

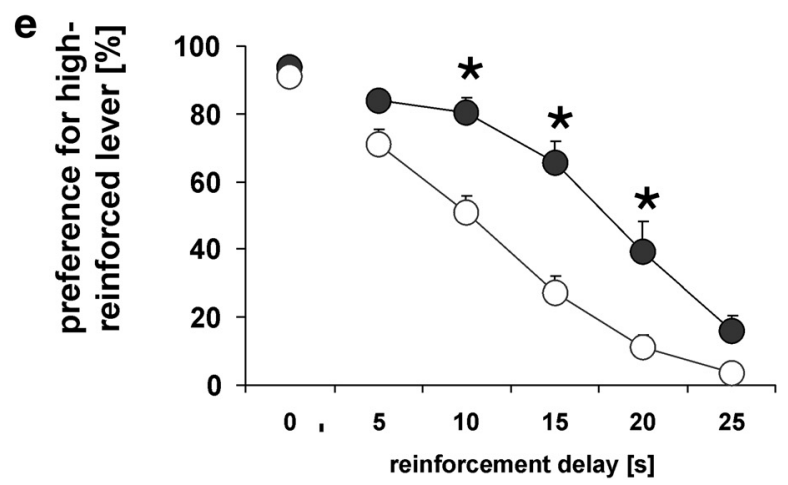

h

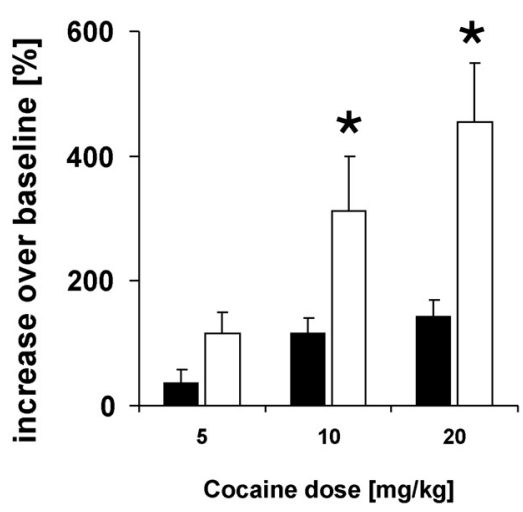

Figure 5. Reward-related behavior in Cnr1 MT and WT animals. Limited-access SCM intake was significantly increased in adult MT $(p=0.00002)(\boldsymbol{a})$, but not adolescent MT rats $(p=0.083)$, compared with age-matched WT animals, indicating a ceiling effect in adolescent rats $(\boldsymbol{b})$. During PR responding, the highest completed ratio $(p=0.0001)$ and the inactivity ratio $(p=0.000002)$ were significantly enhanced in MT rats (c). Social play, a highly rewarding social activity most pronounced during mid-adolescence, was strongly enhanced in MT rats compared with WT controls (attacks received: $p=0.0005$; attacks initiated: $p=0.0002$; pinning: $p=0.014$ ) (d). Morever, impulsive choice was increased in MT compared with WT animals during delay discounting testing (interaction effect: $\left.F_{(5,100)}=4.9, p<0.001\right)(\boldsymbol{e})$. MT rats were also found to show increased reward sensitivity toward the rewarding effects of cocaine. (PP for cocaine $(p=0.007)(\boldsymbol{f})$, cocaine-induced sensitization (genotype effect: $\left.F_{(1,24)}=13.1, p=0.003\right)(\boldsymbol{g})$ and the acute stimulatory effects of cocaine $(\boldsymbol{h})$ were also increased in MT rats compared with WT controls (interaction effect: $\left.F_{(2,34)}=5.3, p=0.01\right)$. Data are indicated as means \pm SEM (SCM intake, PR:MT: $n=13$, WT $n=10$; social play:MT: $n=11$, WT $n=9$; delay discounting: MT: $n=13$, WT $n=9 ;$ cocaine (PP: MT: $n=6$, WT $n=8$; cocaine sensitization: MT: $n=6$, WT $n=8$; cocaine dose-response curve: MT: $n=7$, WT $n=12 ;{ }^{*} p \leq 0.05$ ).

endocannabinoid levels and no differences were observed between the genotypes for the two main endocannabinoids, AEA and 2-AG (Fig. 2i,j). Comparable results were obtained in the hippocampus for expression of CB1R and different components of the eCB system (Fig. 3), indicating that MT rats show only minor compensatory alterations within the $\mathrm{eCB}$ system.

Enhanced eCB signaling has been reported to occur transiently during mid-adolescence (Rodríguez de Fonseca et al., 1993; Schneider, 2008; Klugmann et al., 2011), leading to our hypothesis that the $\mathrm{F} 238 \mathrm{~L}$ mutation in $\mathrm{Cnrl}^{\mathrm{F} 238 \mathrm{~L}}$ rats may sustain features of an adolescent brain into adulthood, which was confirmed by behavioral analysis. Therefore, adult MT rats showed more risk-taking behavior in the EPM, open-field, and EMT tests (Fig. $4 a-d$ ) and enhanced novelty seeking (Fig. $4 e, f)$. Risk-based decision making measured by the PORT task (Dent et al., 2014) differed significantly between genotypes, with increased risk seeking in MT rats (Fig. 4h); reward collection per se differed significantly between the genotypes only in an unfamiliar context (Fig. $4 g$ ).

Reward-related behaviors were also enhanced in MT animals. Food reward intake and operant responding for SCM were significantly increased in adult MT compared with WT rats (Fig. $5 a, c)$. Interestingly, when tested as adolescents, reward intake was also substantially increased in WT and did not differ significantly from MT rats anymore (Fig. $5 b$ ), indicating a ceiling effect during adolescence. MT rats also engaged significantly more in social 


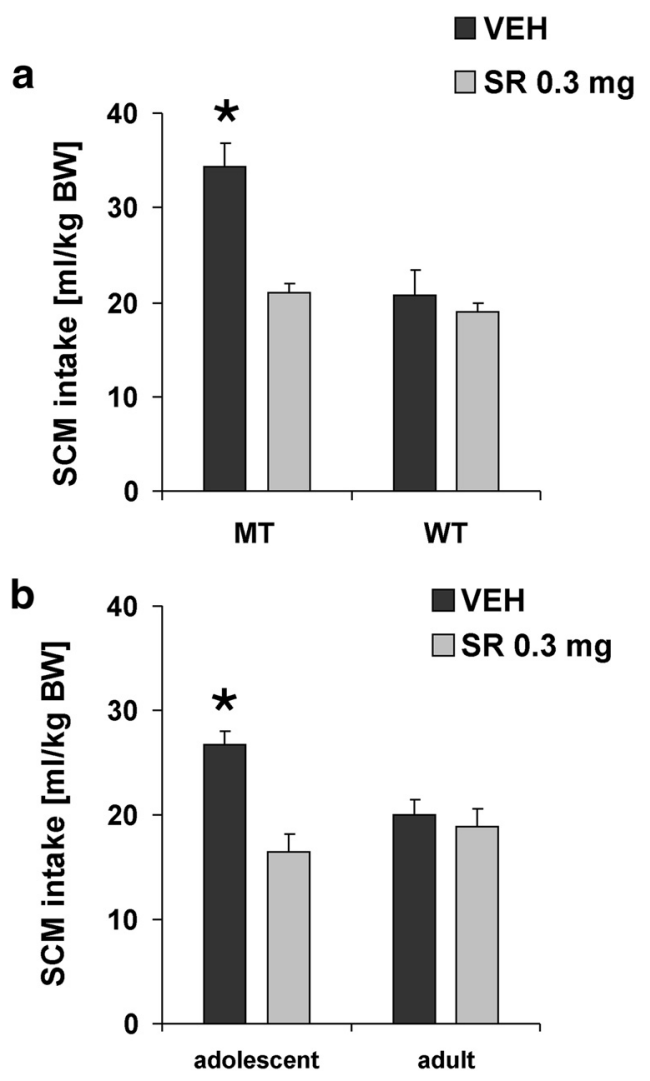

Figure 6. Effects of the CB1R antagonist/inverse agonist SR141716 (SR) on palatable food intake in MT/WT animals $(\boldsymbol{a})$ and adolescent/adult Fischer344 rats $(\boldsymbol{b})$. A low dose of SR $(0.3$ $\mathrm{mg} / \mathrm{kg}$ ) was found to significantly attenuate intake of SCM in MT and adolescent Fischer rats to intake levels of WT or adult Fischer rats, respectively, whereas $0.3 \mathrm{mg} / \mathrm{kg}$ SR had no effect on SCM intake in WT animals and adult Fischer rats (WT/MT: interaction effect: $F_{(1,19)}=19.5, p<$ 0.001; adolescent/adult: interaction effect: $\left.F_{(1,15)}=11.8, p=0.004\right)$. Effects of $S R$ or vehicle (VEH) on SCM intake were tested in a within-subject design. Data are indicated as means \pm SEM (MT: SR/VEH $n=10$, WT: SR/VEH $n=11$; adolescent: SR/VEH $n=8$, adult: SR/VEH $=9$; $\left.{ }^{*} p \leq 0.05\right)$.

play behavior, which has a high incentive value during adolescence (Schneider et al., 2014) (Fig. 5d). Impulsivity is considered a multidimensional concept and impulsive choice is of particular interest for research on adolescent decision making (Blakemore and Robbins, 2012) and is enhanced in adolescent rats (Doremus-Fitzwater et al., 2012). Impulsive choice behavior was assessed with the delay-discounting test, in which MT rats showed increased impulsivity (Fig. 5e). Finally, susceptibility toward the effects of cocaine was tested (Fig. $5 f-h$ ). A significantly higher CPP, increased development and expression of cocaine sensitization and enhanced acute stimulatory effects of cocaine were detected in MT rats. WT rats from the Fischer strain showed only a mild reaction toward the stimulating and rewarding aspects of cocaine, which is consistent with previous studies reporting very poor behavioral and molecular reactions to cocaine and other nondrug rewards in the Fischer strain (Kosten et al., 1997; Brand et al., 2012). We recently reported decreased CB1R expression and attenuated activation of eCB signaling pathways and concomitant diminished reward processing in Fischer rats compared with the Wistar strain (Brand et al., 2012). The present data indicate that decreased eCB signaling in Fischer rats may also contribute to diminished behavioral response toward cocaine, which is ameliorated by introduction of the Cnrl point mutation and subsequently enhanced CB1R functionality. In summary, adult MT rats show an adolescence-like phenotype with high risk and novelty seeking, strongly enhanced peer interaction, increased impulsivity, and a higher sensitivity toward natural and drug rewards.

With an additional experiment, we tested whether partial inhibition of CB1R activity in $\mathrm{Cnr} 1^{\mathrm{F} 238 \mathrm{~L}}$ mutant rats would lead to a WT phenotype. For this, we selected a subthreshold dose of the CB1R antagonist/inverse agonist SR141716 (0.3 mg/kg) that did not affect behavior in adult WT littermates (Fig. $6 a$ ). In contrast, administration of this subthreshold dose completely normalized reward seeking behavior in adult MT rats. Therefore, SR141716 reduced SCM consumption in MT to WT/adult performance levels (Fig. 6a). Similarly, when we applied this subthreshold dose of SR141716 to adolescent Fischer rats, SCM consumption dropped to levels seen in adult Fischer rats. The intake of SCM was not affected by SR141716 subthreshold treatment in adult Fischer rats (Fig. 6b).

Finally, we sought to demonstrate that the basic neurobiological and behavioral features observed in adult MT rats do indeed resemble adolescent features in the Fischer strain. Therefore, we compared adolescent and adult WT Fischer rats directly in a selection of measures previously assessed in MT rats (Fig. 7). Consistent with our earlier findings (Klugmann et al., 2011), striatal CB1R protein levels were higher in adolescent than adult Fischer rats. No age-specific differences were detected for PPR and the amplitude of sEPSC, but, as in MT rats, sEPSC interevent interval was significantly enhanced in adolescence. Finally, SR141716 induced a stronger potentiation of synaptic transmission (fEPSPs) in adolescent rats. These data implicate that adolescent Fischer rats have enhanced CB1R-binding sites, whereas adult MT rats have a gain of function of the CB1R without changes in total binding sites. Regardless of this molecular difference, the resulting physiological alterations in adolescent WT rats, namely increased CB1R signaling and concomitant diminished neurotransmitter release, largely resemble the neurobiology of the adult brain in MT rats. A similar phenotype as observed in adult MT rats was also found in adolescent Fischer rats, including increased risk taking, reward sensitivity, social play, and a stronger reaction toward the stimulatory effects of cocaine compared with adult rats (Fig. 7), which is consistent with previous behavioral findings in adolescent animals (Spear, 2000). Therefore, at a behavioral level, adolescent WT rats were not distinguishable from adult MT rats.

\section{Discussion}

The $C n r 1^{\text {F238L }}$ MT rats generated here represent the first genetic animal model with enhanced CB1R activity and signaling. Although the mutation induces a gain of function for the activity state of the CB1R, MT rats do not exhibit alterations in the expression of CB1R-binding sites and show only minor changes in the eCB system. Initial in silico modeling of the mutated CB1R predicted that the F238L mutation produces a TMH bundle with more flexibility in key regions associated with receptor activation, making the F238L mutant a more labile receptor that is able to undergo changes associated with activation more easily than WT CB1R. This initial prediction on facilitated receptor activation could be confirmed by enhanced $\left[{ }^{35} \mathrm{~S}\right] \mathrm{GTP} \gamma \mathrm{S}$ binding in striatal tissue of MT rats. No differences were observed in levels of eCBs despite the decrease in protein levels of the eCB-degrading enzyme FAAH. A similar nonlinear relationship between FAAH expression/activity and $\mathrm{eCB}$ levels has been reported in $\mathrm{CB} 1 \mathrm{R}$ knock-out mice, in which a pronounced increase in FAAH levels and functionality in CB1R knock-out was reported, whereas no, 
a

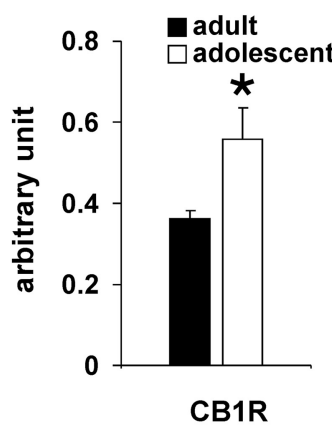

d

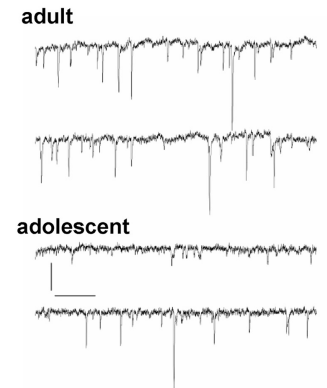

e

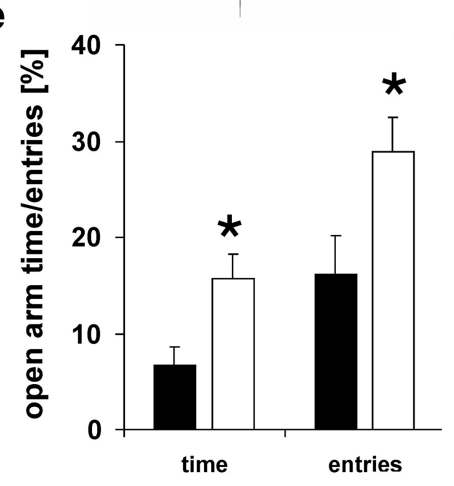

b
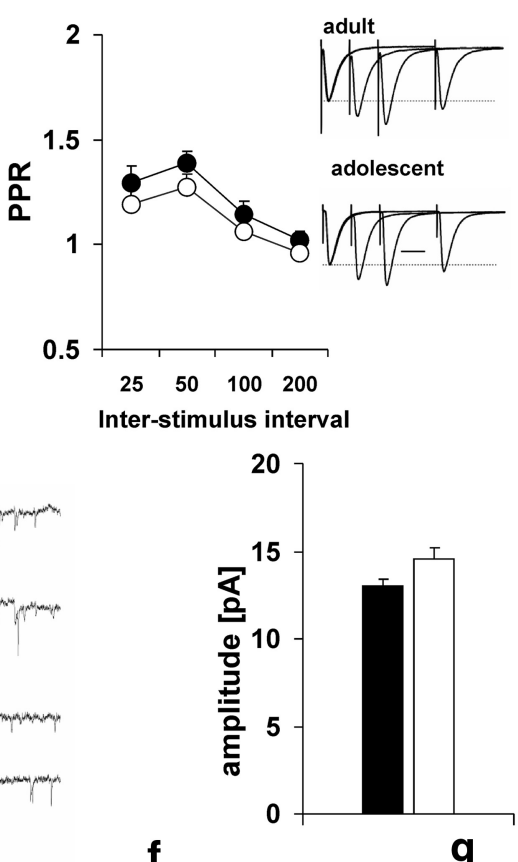

C

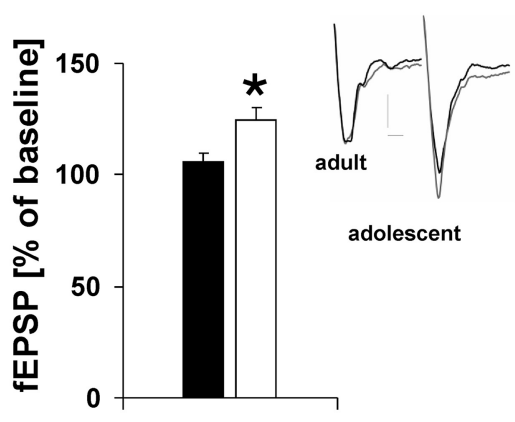

f

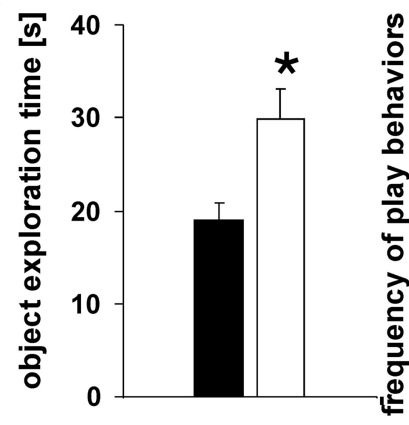

h

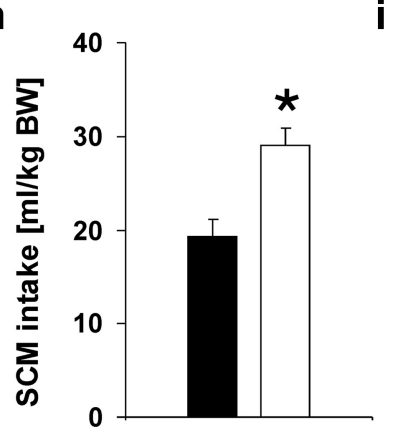

i

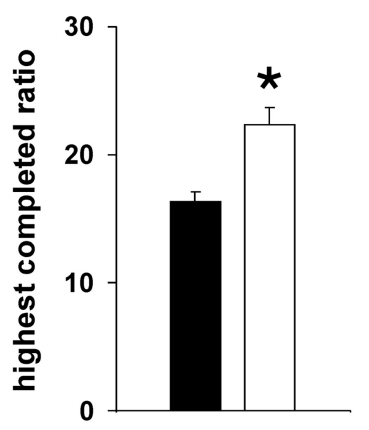

j

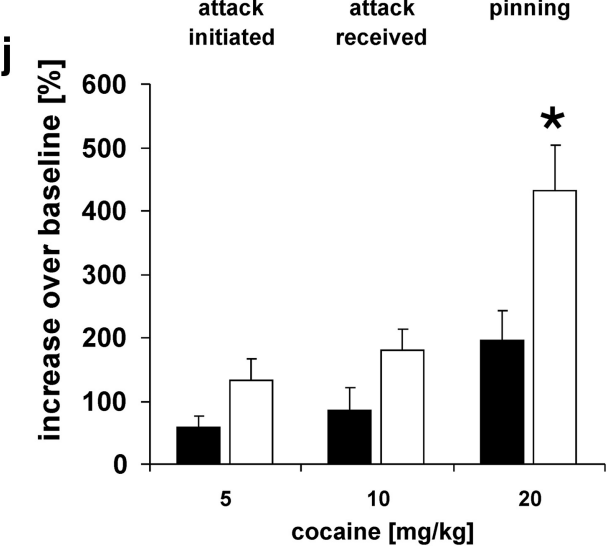

Figure 7. Expression and functionality of the adolescent CB1R and behavioral characterization of adolescent and adult Fischer 344 rats. Striatal CB1R protein levels were higher in adolescent compared with adult rats $(p=0.036)(\boldsymbol{a})$. No differences were found for PPR (age effect: $\left.F_{(1,83)}=3.2, p=0.08\right)$ Representative traces for PPR: EPSC amplitudes are normalized to the peak of the first EPSC. In each example, there are three trials superposed (for three different interstimulus intervals). Scale bar, $20 \mathrm{~ms}$. (b). The CB1R antagonist/inverse agonist SR141716 (SR) was found to exert a stronger effect in adolescent compared with adult rats on fEPSPs $(p=0.033)$. Representative traces of fEPSPs recorded before (black) and after (gray) application of SR141716. Scale bar, $0.1 \mathrm{mV}$; $2 \mathrm{~ms}$ (c). The amplitude of sEPSCs did not differ between the two groups $(p=0.08)$, but, as in MT rats, the sEPSC interevent interval was significantly enhanced in adolescent rats $(p=0.012)$. Representative traces for sEPSC: There are 7 consecutive seconds for each condition (two rows per each). Scale bar, $10 \mathrm{pA} ; 500 \mathrm{~ms}$ (d). Adolescent animals were further screened for a selection of behavioral characteristics observed before in MT animals. Adolescent rats showed increased risk-taking in the EPM (e) compared with adult Fischer rats (EPM: percentage time: $p=0.009$; percentage entries: $p=0.028)$. Exploration of a novel object $(\boldsymbol{f})$ was also increased $(p=0.009)$. Adolescent Fischer rats showed an increase in reward-related behaviors compared with adult rats. Intake of a palatable food reward $(\boldsymbol{g})$, as well as PR responding $(\boldsymbol{h})$, was significantly higher in adolescents than adults (intake: $p=0.001 ;$ PR testing: $p=0.004$ ). Social play behavior was also strongly increased in adolescent animals $(i)$ compared with adult controls (attacks received, initiated and pinning: $p<0.001$ ). Finally, the acute stimulatory effects of cocaine $(j)$ were significantly enhanced in adolescence compared with adulthood $\left(F_{(2,40)}=3.3, p=0.047\right)$. Data are indicated as means \pm SEM (CB1R Western blot: $n=5 ;$ PPR: adolescent: $n=11$, adult $n=12 ;$ sEPSC: adolescent: $n=11$, adult $n=10$; effects of SR on fEPSP: $n=6$; EPM, novel object exploration, food reward intake, PR: $n=12$; social play: $n=9$; cocaine dose-response curve: adolescent: $n=$ 12 , adult $n=10)$. 
or only minor, changes were detected in AEA and 2-AG levels (Maccarrone et al., 2001; Maccarrone et al., 2002).

In the present study, the MT rat model was used to gain molecular insights into adolescent behavior, but this genetic model will also be of great use for many research questions in the cannabinoid research field. In respect to adolescent behavior, adult Cnr1 MT rats exhibit an adolescent-like phenotype that is not distinguishable from adolescent WT rats. Likewise, similarities in CB1R functionality could also be observed between adult MT rats and adolescent Fischer WT rats, further confirming that enhanced CB1R activity is critical involved in driving adolescent behavior. In particular, when considering the enhanced pharmacological reactivity in these animals, we conclude that CB1R signaling is enhanced in both conditions but for different reasons: increased receptor activity in Cnrl MT rats versus increased receptor expression in adolescence. In conclusion, adolescent behavior seems to be driven by enhanced CB1R functionality because MT rats that have an inherent gain of function of this receptor show a persistent adolescent behavioral profile that is preserved into adulthood. The present observation of an adolescent-like phenotype in adult Cnrl MT rats, together with reports on enhanced CB1R signaling during adolescence (Rodríguez de Fonseca et al., 1993; Klugmann et al., 2011), therefore emphasizes a pivotal role of eCB signaling in an adolescent brain, which may also underlie increased neuroplasticity and concomitant complex and transient adolescent behavioral adaptations. Notably, when tested as adolescents, WT and MT animals no longer differed significantly in reward-related behavior, indicating a ceiling effect of the adolescent phenotype in MT that cannot be further increased during the adolescent period. Therefore, our data strongly implicate enhanced CB1R activity in increased risk and novelty seeking, impulsive choice, social play behavior, and reward processing for food and drug rewards.

Detailed mechanisms on adolescent brain development are still only poorly understood. This is a crucial deficit in knowledge considering that adolescents appear to be specifically vulnerable to suboptimal choices and the emergence of neuropsychiatric disorders (Kessler et al., 2007; Paus et al., 2008; Merikangas et al., 2009) that arise from these transient but drastic behavioral and neurological adaptations during adolescence. The eCB system constitutes an ideal candidate for mediating these adaptational changes. Because presynaptic CB1R is probably the most abundant G-protein-coupled receptor in the mammalian brain, the $\mathrm{eCB}$ system plays a critical role as a modulator of excitatory/inhibitory balance throughout the entire CNS and is crucial for the maintenance of the organism's homeostasis (Kano et al., 2009; Castillo et al., 2012).

One important question concerns the neurobiological consequences of enhanced CB1R activity in the adolescent brain. A recent study reported elevated firing activity of ventral tegmental area (VTA) dopamine neurons in adolescent compared with adult rats (McCutcheon et al., 2012). Similar to our findings, this study also detected a decreased frequency in AMPAR-mediated sEPSCs in adolescent animals without concomitant changes in PPR, potentially involving a decreased GABAergic tone (McCutcheon et al., 2012). These findings on increased dopaminergic and decreased GABAergic signaling are consistent with our present observation of an increased activity state of CB1R during adolescence. Inhibitory effects of presynaptic CB1R activation on GABA are well established (Kano et al., 2009). An indirect cannabinoid-mediated stimulation of dopaminergic signaling has also been described (Lupica and Riegel, 2005). Notably, cannabinoid-mediated pharmacological effects were highly aug- mented to a comparable extent in adult MT and adolescent WT rats, which is consistent with the heightened susceptibility of an adolescent brain toward adverse and persistent cannabinoid effects reported in human studies and animal research (Schneider, 2008; Chadwick et al., 2013; Schneider, 2013). CB1R function was first evaluated by assessing the effects of SR141716 on striatal fEPSPs. Whereas SR141716 application had no consequences in adult WT rats, it induced a potentiation of synaptic transmission in slices from adult MT and adolescent WT rats, which further supports a tonic activity of the adult mutated and the WT adolescent CB1R. This finding could also be confirmed on the systemic level, where administration of the CB1R antagonist/inverse agonist SR141716 was found to exert a stronger effect on behavioral performance in adult MT and adolescent Fischer rats compared with the respective controls. It has been well documented in various studies in vivo and in vitro that SR141716 behaves as an inverse agonist rather than a neutral antagonist. Therefore, its biochemical or behavioral effects generally are opposite to the effects of cannabinoid agonists and include, among others, inhibition of MAPK activity, adenylyl cyclase activity, and GTP $\gamma S$ binding in selected brain regions (Pertwee, 2005; Bergman et al., 2008). It has been suggested that SR141716 binds preferentially to the so-called inactive R state of the CB1R, thereby decreasing the activation of the signaling pathway (Lange and Kruse, 2005; Pertwee, 2005). Therefore, the lower availability of CB1R in WT and adult Fischer rats might well explain the reduced behavioral effects of the low dose of SR141716 in these animals, considering its inverse cannabimimetic action at the receptor. Therefore, one neurobiological consequence of enhanced and tonic CB1R activity in the adolescent brain may be a decreased GABAergic tone (McCutcheon et al., 2012) within the VTA. A subsequent consequence of a decreased GABAergic tone is enhanced dopaminergic activity that in turn can drive increased novelty seeking and increased reward processing for food and drug rewards in rodents as well as in humans (Spanagel and Weiss, 1999; Zald et al., 2008). A similar mechanism has been described in the prefrontal cortex, where enhanced CB1R activity causes a functional downregulation of GABAergic transmission in the adolescent brain (Cass et al., 2014) that in turn may mediate increased risk and impulsive behavior (Jupp et al., 2013).

In summary, the adolescent state comprises a complex behavioral phenotype that bears many vulnerability factors for suboptimal behavioral choices and psychiatric disorders (Paus et al., 2008; Merikangas et al., 2009). Understanding the basis of these disorders therefore requires a comprehensive knowledge of how molecular processes affect and trigger behavior during adolescence. We conclude that the activity state of the CB1R is an important molecular mediator of adolescent behavior.

\section{References}

Adriani W, Boyer F, Gioiosa L, Macrì S, Dreyer JL, Laviola G (2009) Increased impulsive behavior and risk proneness following lentivirusmediated dopamine transporter over-expression in rats' nucleus accumbens. Neuroscience 159:47-58. CrossRef Medline

Ahn K, Johnson DS, Mileni M, Beidler D, Long JZ, McKinney MK, Weerapana E, Sadagopan N, Liimatta M, Smith SE, Lazerwith S, Stiff C, Kamtekar S, Bhattacharya K, Zhang Y, Swaney S, Van Becelaere K, Stevens RC, Cravatt BF (2009) Discovery and characterization of a highly selective FAAH inhibitor that reduces inflammatory pain. Chem Biol 16: 411-420. CrossRef Medline

Ahuja S, Hornak V, Yan EC, Syrett N, Goncalves JA, Hirshfeld A, Ziliox M, Sakmar TP, Sheves M, Reeves PJ, Smith SO, Eilers M (2009) Helix movement is coupled to displacement of the second extracellular loop in rhodopsin activation. Nat Struct Mol Biol 16:168-175. CrossRef Medline Anavi-Goffer S, Fleischer D, Hurst DP, Lynch DL, Barnett-Norris J, Shi S, 
Lewis DL, Mukhopadhyay S, Howlett AC, Reggio PH, Abood ME (2007) Helix 8 Leu in the CB1 cannabinoid receptor contributes to selective signal transduction mechanisms. J Biol Chem 282:25100-25113. CrossRef Medline

Bergman J, Delatte MS, Paronis CA, Vemuri K, Thakur GA, Makriyannis A (2008) Some effects of CB1 antagonists with inverse agonist and neutral biochemical properties. Physiol Behav 93:666-670. CrossRef Medline

Bertalovitz AC, Ahn KH, Kendall DA (2010) Ligand Binding Sensitivity of the Extracellular Loop Two of the Cannabinoid Receptor 1. Drug Dev Res 71:404-411. CrossRef Medline

Bhandarkar M, Brunner R, Chipot C, Dalke A, Dixit S, Grayson P, Gullingsrud J, Gursoy A, Hardy D, Humphrey W, Hurwitz D, Krawetz N, Nelson M, Phillips J, Shinozaki A, Zheng G, Zhu F (2003) NAMD User's Guide Version 2.5. Available at http://www.ks.uiuc.edu/Research/namd/2.5/ug. pdf. Urbana, IL: Theoretical Biophysics Group, Beckman Institute, University of Illinois.

Blakemore SJ, Robbins TW (2012) Decision-making in the adolescent brain. Nat Neurosci 15:1184-1191. CrossRef Medline

Brand T, Spanagel R, Schneider M (2012) Decreased reward sensitivity in rats from the Fischer344 strain compared to Wistar rats is paralleled by differences in endocannabinoid signaling. PLoS One 7:e31169. CrossRef Medline

Casey BJ, Jones RM, Hare TA (2008) The adolescent brain. Ann N Y Acad Sci 1124:111-126. CrossRef Medline

Cass DK, Flores-Barrera E, Thomases DR, Vital WF, Caballero A, Tseng KY (2014) CB1 cannabinoid receptor stimulation during adolescence impairs the maturation of GABA function in the adult rat prefrontal cortex. Mol Psychiatry 19:536-543. CrossRef Medline

Castillo PE, Younts TJ, Chávez AE, Hashimotodani Y (2012) Endocannabinoid signaling and synaptic function. Neuron 76:70-81. CrossRef Medline

Chadwick B, Miller ML, Hurd YL (2013) Cannabis use during adolescent development: susceptibility to psychiatric illness. Front Psychiatry 4:129. Medline

Dent CL, Isles AR, Humby T (2014) Measuring risk-taking in mice: balancing the risk between seeking reward and danger. Eur J Neurosci 39:520530. CrossRef Medline

Doremus-Fitzwater TL, Barreto M, Spear LP (2012) Age-related differences in impulsivity among adolescent and adult Sprague-Dawley rats. Behav Neurosci 126:735-741. CrossRef Medline

Eaton DK, Kann L, Kinchen S, Shanklin S, Ross J, Hawkins J, Harris WA, Lowry R, McManus T, Chyen D, Lim C, Whittle L, Brener ND, Wechsler H; Centers for Disease Control and Prevention (CDC) (2010) Youth risk behavior surveillance - United States, 2009. MMWR Surveill Summ 59:1-142. Medline

Fegley D, Gaetani S, Duranti A, Tontini A, Mor M, Tarzia G, Piomelli D (2005) Characterization of the fatty acid amide hydrolase inhibitor cyclohexyl carbamic acid 3'-carbamoyl-biphenyl-3-yl ester (URB597): effects on anandamide and oleoylethanolamide deactivation. J Pharmacol Exp Ther 313:352-358. Medline

Feller SE, MacKerell AD (2000) An improved empirical potential energy function for molecular simulations of phospholipids. J Phys Chem B 104:7510-7515. CrossRef

Friemel CM, Spanagel R, Schneider M (2010) Reward sensitivity for a palatable food reward peaks during pubertal development in rats. Front Behav Neurosci 4:39. Medline

Goepfrich AA, Gluch C, Friemel CM, Schneider M (2013) Behavioral differences in three Wistar Han rat lines for emotional reactivity, cognitive processing and ethanol intake. Physiol Behav 110-111:102-108. CrossRef Medline

Grosse J, Tarnow P, Römpler H, Schneider B, Sedlmeier R, Huffstadt U, Korthaus D, Nehls M, Wattler S, Schöneberg T, Biebermann H, Augustin M (2006) N-ethyl-N-nitrosourea-based generation of mouse models for mutant $\mathrm{G}$ protein-coupled receptors. Physiol Genomics 26:209-217. CrossRef Medline

Humphrey W, Dalke A, Schulten K (1996) VMD: visual molecular dynamics. J Mol Graph 14:33-38. CrossRef Medline

Jupp B, Caprioli D, Saigal N, Reverte I, Shrestha S, Cumming P, Everitt BJ, Robbins TW, Dalley JW (2013) Dopaminergic and GABA-ergic markers of impulsivity in rats: evidence for anatomical localisation in ventral striatum and prefrontal cortex. Eur J Neurosci 37:1519-1528. CrossRef Medline

Kano M, Ohno-Shosaku T, Hashimotodani Y, Uchigashima M, Watanabe M
(2009) Endocannabinoid-mediated control of synaptic transmission. Physiol Rev 89:309-380. CrossRef Medline

Kasanetz F, Manzoni OJ (2009) Maturation of excitatory synaptic transmission of the rat nucleus accumbens from juvenile to adult. J Neurophysiol 101:2516-2527. Medline

Kasanetz F, Deroche-Gamonet V, Berson N, Balado E, Lafourcade M, Manzoni O, Piazza PV (2010) Transition to addiction is associated with a persistent impairment in synaptic plasticity. Science 328:1709-1712. CrossRef Medline

Kessler RC, Amminger GP, Aguilar-Gaxiola S, Alonso J, Lee S, Ustün TB (2007) Age of onset of mental disorders: a review of recent literature. Curr Opin Psychiatry 20:359-364. CrossRef Medline

Klugmann M, Klippenstein V, Leweke FM, Spanagel R, Schneider M (2011) Cannabinoid exposure in pubertal rats increases spontaneous ethanol consumption and NMDA receptor associated protein levels. Int J Neuropsychopharmacol 14:505-517. CrossRef Medline

Kosten TA, Miserendino MJ, Haile CN, DeCaprio JL, Jatlow PI, Nestler EJ (1997) Acquisition and maintenance of intravenous cocaine selfadministration in Lewis and Fischer inbred rat strains. Brain Res 778: 418-429. CrossRef Medline

Lange JH, Kruse CG (2005) Keynote review: Medicinal chemistry strategies to CB1 cannabinoid receptor antagonists. Drug Discov Today 10:693-702. CrossRef Medline

Li Q, Liu Z, Monroe H, Culiat CT (2002) Integrated platform for detection of DNA sequence variants using capillary array electrophoresis. Electrophoresis 23:1499-1511. CrossRef Medline

Lupica CR, Riegel AC (2005) Endocannabinoid release from midbrain dopamine neurons: a potential substrate for cannabinoid receptor antagonist treatment of addiction. Neuropharmacology 48:1105-1116. CrossRef Medline

Maccarrone M, Attinà M, Bari M, Cartoni A, Ledent C, Finazzi-Agrò A (2001) Anandamide degradation and N-acylethanolamines level in wildtype and CB1 cannabinoid receptor knockout mice of different ages. J Neurochem 78:339-348. CrossRef Medline

Maccarrone M, Valverde O, Barbaccia ML, Castañé A, Maldonado R, Ledent C, Parmentier M, Finazzi-Agrò A (2002) Age-related changes of anandamide metabolism in CB1 cannabinoid receptor knockout mice: correlation with behaviour. Eur J Neurosci 15:1178-1186. CrossRef Medline

MacKerell AD, Bashford D, Bellot R, Dunbrack RL, Evanseck JD, Field MJ, Fischer S, Gao J, Guo H, Ha S, Joseph-McCarthy D, Kuchnir L, Kuczera K, Lau FTK, Mattos C, Michnick S, Ngo T, Nguyen DT, Prodhom B, Reiher WE, et al. (1998) All-atom empirical potential for molecular modeling and dynamics studies of proteins. J Phys Chem B 102:3586-3616. Medline

McAllister SD, Hurst DP, Barnett-Norris J, Lynch D, Reggio PH, Abood ME (2004) Structural mimicry in class A G protein-coupled receptor rotamer toggle switches: the importance of the F3.36(201)/W6.48(357) interaction in cannabinoid CB1 receptor activation. J Biol Chem 279:4802448037. CrossRef Medline

McCutcheon JE, Conrad KL, Carr SB, Ford KA, McGehee DS, Marinelli M (2012) Dopamine neurons in the ventral tegmental area fire faster in adolescent rats than in adults. J Neurophysiol 108:1620-1630. CrossRef Medline

Merikangas KR, Nakamura EF, Kessler RC (2009) Epidemiology of mental disorders in children and adolescents. Dialogues Clin Neurosci 11:7-20. Medline

Miederer I, Maus S, Zwiener I, Podoprygorina G, Meshcheryakov D, Lutz B, Schreckenberger M (2013) Evaluation of cannabinoid type 1 receptor expression in the rat brain using [F]MK-9470 microPET. Eur J Nucl Med Mol Imaging 40:1739-1747. CrossRef Medline

Paus T, Keshavan M, Giedd JN (2008) Why do many psychiatric disorders emerge during adolescence? Nat Rev Neurosci 9:947-957. Medline

Pertwee RG (2005) Inverse agonism and neutral antagonism at cannabinoid CB1 receptors. Life Sci 76:1307-1324. CrossRef Medline

Phillips JC, Braun R, Wang W, Gumbart J, Tajkhorshid E, Villa E, Chipot C, Skeel RD, Kalé L, Schulten K (2005) Scalable molecular dynamics with NAMD. J Comput Chem 26:1781-1802. CrossRef Medline

Rodríguez de Fonseca F, Ramos JA, Bonnin A, Fernández-Ruiz JJ (1993) Presence of cannabinoid binding sites in the brain from early postnatal ages. Neuroreport 4:135-138. CrossRef Medline

Schneider M (2008) Puberty as a highly vulnerable developmental period 
for the consequences of cannabis exposure. Addict Biol 13:253-263. CrossRef Medline

Schneider M (2013) Adolescence as a vulnerable period to alter rodent behavior. Cell Tissue Res 354:99-106. CrossRef Medline

Schneider M, Schömig E, Leweke FM (2008) Acute and chronic cannabinoid treatment differentially affects recognition memory and social behavior in pubertal and adult rats. Addict Biol 13:345-357. CrossRef Medline

Schneider M, Heise V, Spanagel R (2010) Differential involvement of the opioid receptor antagonist naloxone in motivational and hedonic aspects of reward. Behav Brain Res 208:466-472. CrossRef Medline

Schneider P, Hannusch C, Schmahl C, Bohus M, Spanagel R, Schneider M (2014) Adolescent peer-rejection persistently alters pain perception and $\mathrm{CB} 1$ receptor expression in female rats. Eur Neuropsychopharmacol 24: 290-301. CrossRef Medline

Simon NW, Moghaddam B (2015) Neural processing of reward in adolescent rodents Dev Cogn Neurosci 11:145-154.

Spanagel R, Weiss F (1999) The dopamine hypothesis of reward: past and current status. Trends Neurosci 22:521-527. CrossRef Medline
Spear LP (2000) The adolescent brain and age-related behavioral manifestations. Neurosci Biobehav Rev 24:417-463. CrossRef Medline

Steindel F, Lerner R, Häring M, Ruehle S, Marsicano G, Lutz B, Monory K (2013) Neuron-type specific cannabinoid-mediated G protein signalling in mouse hippocampus. J Neurochem 124:795-807. CrossRef Medline

van Boxtel R, Cuppen E (2011) Generation of genetically modified rodents using random ENU mutagenesis. Methods Mol Biol 693:295-308. CrossRef Medline

van Boxtel R, Vroling B, Toonen P, Nijman IJ, van Roekel H, Verheul M, Baakman C, Guryev V, Vriend G, Cuppen E (2011) Systematic generation of in vivo $\mathrm{G}$ protein-coupled receptor mutants in the rat. Pharmacogenomics J 11:326-336. CrossRef Medline

Zald DH, Cowan RL, Riccardi P, Baldwin RM, Ansari MS, Li R, Shelby ES, Smith CE, McHugo M, Kessler RM (2008) Midbrain dopamine receptor availability is inversely associated with novelty-seeking traits in humans. J Neurosci 28:14372-14378. CrossRef Medline 